\title{
Antecedentes y perspectivas de algunas enfermedades prioritarias que afectan a la ganadería bovina en México
}

Carmen Rojas Martínez ${ }^{a}$

Elizabeth Loza Rubio ${ }^{\mathrm{b}}$

Sergio Darío Rodríguez Camarillo a

Julio Vicente Figueroa Millán ${ }^{\text {a }}$

Francisco Aguilar Romero ${ }^{b}$

Rodolfo Esteban Lagunes Quintanilla ${ }^{\text {a }}$

José Francisco Morales Álvarez ${ }^{\mathrm{b}}$

Marco Antonio Santillán Flores ${ }^{b}$

Guadalupe Asunción Socci Escatell ${ }^{\text {b }}$

Jesús Antonio Álvarez Martínez ${ }^{\mathrm{a}^{*}}$

${ }^{a}$ Instituto Nacional de Investigaciones Forestales, Agrícolas y Pecuarias. CENID Salud Animal e Inocuidad, Carretera Cuernavaca-Cuautla 8534. Col. Progreso Jiutepec, 62574 Morelos. México.

b Instituto Nacional de Investigaciones Forestales, Agrícolas y Pecuarias. CENID Salud Animal e Inocuidad. Ciudad de México. México.

*Autor de correspondencia: alvarez.jesus@inifap.gob.mx

\section{Resumen:}

La revisión se enfocó en presentar de manera concisa las aportaciones que investigadores del INIFAP, han desarrollado directamente o en colaboración con investigadores de otras 
instituciones sobre diferentes aspectos de las enfermedades que afectan a la ganadería bovina en México. Se describen investigaciones sobre enfermedades virales como la rabia y la diarrea viral bovina; bacterianas como la anaplasmosis, brucelosis, tuberculosis, paratuberculosis, leptospirosis y enfermedad respiratoria bovina; de las enfermedades parasitarias se incluye a la infestación por garrapatas y a la babesiosis. Se identifican posibles líneas de investigación que pueden coadyuvar a mitigar el impacto de las enfermedades en la producción. Se señalan aportes sobre el desarrollo o adaptación de técnicas diagnósticas de tipo serológico y molecular y se considera el diagnóstico de resistencia a los ixodicidas. Además, se indican parámetros epidemiológicos de las enfermedades y se refieren los biológicos generados que comprenden vacuna contra rabia, anaplasmosis y babesiosis; bacterina contra leptospirosis y una bacterina-toxoide contra neumonías. Asimismo, se comentan las evaluaciones del uso de BCG contra tuberculosis y una vacuna de nueva generación contra la brucelosis. En la revisión se concluye que la investigación del INIFAP en salud animal debe forzosamente tener como perspectiva las ciencias ómicas. Solo así se complementará el entendimiento de los mecanismos de las enfermedades, el desarrollo de nuevas técnicas diagnósticas y el diseño de vacunas efectivas y seguras. De modo que el gran reto será el involucramiento del área de salud animal al concepto de "Una Salud".

Palabras clave: Enfermedades, Vacunas, Prevención, Control.

Recibido: 11/11/2020

Aceptado: 08/03/2021

\section{Introducción}

La producción ganadera tiene como propósito producir alimentos de calidad, asequibles para la sociedad y que se obtengan en un ambiente sustentable; lo cual, es difícil ante una creciente necesidad de carne y leche. Por lo que investigadores del INIFAP mantienen una constante atención a las demandas de los productores, mediante la generación de conocimientos científicos e innovación tecnológica en los problemas de salud animal.

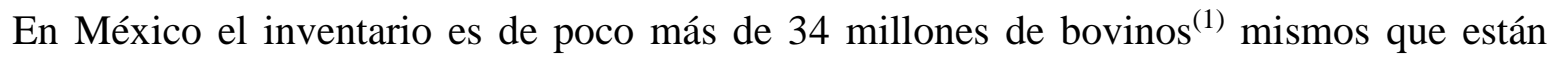
expuestos a agentes patógenos de naturaleza viral, bacteriana o parasitaria, los que con frecuencia se comportan como coinfecciones o complejos. Las enfermedades presentan una distribución y frecuencia que varía de acuerdo a las interacciones entre el agente patógeno, el hospedador bovino y las condiciones ecológicas. Su presentación ocasiona diferentes tasas de morbilidad, mortalidad y baja productividad, con un efecto detrimental en el 
aprovechamiento del potencial de producción. De manera inherente, se generan restricciones del comercio nacional e internacional; se ha estimado que un brote de enfermedad puede afectar el $20 \%$ de las actividades comerciales del hato ${ }^{(2)}$. En las enfermedades se involucra una amplia variabilidad de la relación costo-beneficio de los programas de prevención y control; lo cual genera subestimaciones de los impactos en la producción y por ende hay inconsistencia en la información sobre las pérdidas. Asimismo, es importante remarcar que algunas enfermedades de los bovinos afectan a la población humana ${ }^{(3)}$. Cada enfermedad tiene una carga económica diferente que se determina a través de los costos directos, indirectos del consumo o de la pérdida de recursos; en términos generales incluye recursos humanos, estructurales y económicos. El objetivo de esta revisión es presentar de manera concisa, las aportaciones que investigadores del INIFAP han realizado, directamente o en colaboración con investigadores de otras instituciones, sobre diferentes aspectos de las principales enfermedades que afectan a la ganadería bovina en México. Al mismo tiempo se trata de identificar líneas de investigación que permitan mitigar el impacto de las enfermedades en la producción.

\section{Rabia paralítica bovina}

La rabia paralítica bovina (RPB) o derriengue es una encefalitis causada por un virus ARN de polaridad negativa de la familia Rhabdoviridae y del género Lyssavirus. En México el principal transmisor es el quiróptero Desmodus rotundus que es un murciélago hematófago, cuya distribución en América Latina es desde las costas de México hasta el Norte de Argentina $^{(4)}$. En México es una enfermedad frecuente, en el año 2019 se diagnosticaron 284 $\operatorname{casos}_{\operatorname{positivos}}^{(5)}$.

\section{Aportes del INIFAP}

Diagnóstico. En países endémicos como México, el diagnóstico es crítico para la prevención y control de la rabia. La prueba de referencia es la inmunofluorescencia directa (IFD); sin embargo, en climas tropicales frecuentemente ocurre la descomposición del tejido cerebral cuando se manipula, lo cual imposibilita la ejecución del diagnóstico o deriva en resultados falsos negativos. Por lo que, a partir de secuencias de 40 aislamientos de virus provenientes de diferentes reservorios y zonas geográficas del país, se desarrolló una prueba de reacción en cadena de la polimerasa en tiempo real (RT-PCR). Para lo cual, del gene $\mathrm{N}$ que es el más conservado del virus, se diseñaron iniciadores. Con la aplicación de la prueba se obtuvieron tasas de sensibilidad, especificidad y valor predictivo de 86,91 y $96 \%$, respectivamente ${ }^{(6)}$. También se logró detectar al virus en muestras conservadas a 27 ${ }^{\circ} \mathrm{C}$ durante 23 días. Así, la RT-PCR actualmente se acepta como una excelente alternativa para el diagnóstico del virus ${ }^{(7)}$. 
Epidemiología Molecular. Investigadores del INIFAP han sido pioneros de la caracterización antigénica y molecular del virus de la rabia. Realizaron la detección de variantes antigénicas usando un panel de anticuerpos monoclonales obtenido del Instituto Pasteur en Paris, Francia ${ }^{(8)}$. Posteriormente, utilizando anticuerpos monoclonales del Centro para el Control de Enfermedades de los EE.UU. lograron la caracterización molecular de muestras provenientes de humanos y animales domésticos y silvestres recolectados de 1990 a 1995. Con lo que se reconoció un nuevo ciclo denominado "hipervariables" que circula en zorrillos en Baja California Sur. Al mismo tiempo, se identificaron variantes antigénicas y moleculares que circulaban en vampiros y en otra fauna silvestre ${ }^{(9,10)}$. En un estudio colaborativo con investigadores del Instituto Pasteur, se determinaron los principales ciclos epidemiológicos de rabia en México mediante la técnica de Fragmentos de restricción de longitud polimórfica $(\mathrm{RFLP})^{(8)}$. En otra investigación, usando una porción del gen $\mathrm{P}$ se descubrió que una variante del virus que circula en gato, también lo hace en el murciélago Tadarida brasiliensis ${ }^{(11,12)}$.

Vacunación. Con el uso de radiación gamma con una fuente de Cobalto-60 se logró mantener la potencia, inocuidad, estabilidad y caducidad en vacunas tradicionales ${ }^{(13-16)}$. Para la aplicación de una vacuna génica en perros, se pudo sustituir con éxito a la pistola de genes por una jeringa de insulina ${ }^{(17)}$.

Se generaron vacunas antirrábicas comestibles en las que se usó el gen $\mathrm{N}$ expresado en jitomate, aunque se obtuvo un bajo nivel de inmunogenicidad ${ }^{(18)}$. En contraste con la proteína $\mathrm{G}$ expresada en callos embriogénicos de zanahoria, se alcanzó una protección del $60 \%$ en ratones ${ }^{(19)}$. Posteriormente se produjo una vacuna antirrábica en maíz con la que la protección se incrementó al $80 \%$ en borregos ante un desafío con virus letal ${ }^{(4)}$.

Recientemente en investigaciones colaborativas, se han descubierto diferencias de los receptores tipo Toll (TLR) entre los quirópteros y mamíferos terrestres ${ }^{(20)}$. En la serie Nature se ha publicado el hologenoma del vampiro, y se ha inferido que el murciélago hematófago se ha adaptado a la sangre a través de una estrecha relación entre su genoma y el microbioma intestinal ${ }^{(21)}$.

Perspectivas. En condiciones tropicales el mantenimiento de la cadena fría es un serio inconveniente; por lo que es una exigencia generar una vacuna termoestable que permita su uso a nivel masivo. También, es forzoso aplicar pruebas masivas para detectar anticuerpos neutralizantes que se asocian con protección, para evaluar la efectividad de las vacunas. Además, es esencial producir un conjugado de buena calidad que permita altas tasas de sensibilidad, especificidad y menor costo de la prueba. 


\section{Diarrea viral bovina}

La diarrea viral bovina (DVB) es una enfermedad de distribución mundial que ocasiona importantes pérdidas a la ganadería. El agente causal es un Pestivirus de la familia Flaviviridae, tiene un efecto inmunodepresor que facilita infecciones secundarias o concomitantes. Afecta el sistema digestivo, respiratorio y reproductivo, y es un componente del complejo respiratorio bovino ${ }^{(22)}$. El virus posee alta variabilidad genética, se clasifica en dos genotipos y varios subgenotipos.

\section{Aportes del INIFAP}

Epidemiología. En México la primera descripción de DVB se hizo en 1975, específicamente en bovinos con problemas reproductivos en los que se detectaron anticuerpos circulantes ${ }^{(23)}$. Los estudios realizados por el INIFAP se han limitado a entender la epidemiología y a la medición de factores de riesgo. No obstante, en México se ha demostrado la presencia de los subgenotipos $1 \mathrm{a}, 1 \mathrm{~b}, 1 \mathrm{c}$ y $2 \mathrm{a}^{(24)}$.

En un reporte se describe un muestreo en ganado lechero en diferentes estados del país, en el que se determinó una seroprevalencia de $78.8 \%$. En el mismo estudio los factores de riesgo significativos fueron tamaño de hato, corrales, producción intensiva y periodos interparto largos ${ }^{(25)}$.

Perspectivas. La alta prevalencia de la DVB sugiere la oportunidad para crear líneas de investigación de tipo básico y aplicado para su prevención y control. El reto ideal sería la eliminación de la DVB, para lo cual, se debería desarrollar una vacuna con aislados mexicanos que representen a los subgenotipos presentes. Sería deseable que se desarrollen vacunas de nueva generación, así como técnicas diagnósticas con alta sensibilidad y especificidad que permitan reconocer infecciones concomitantes.

\section{Anaplasmosis bovina}

La anaplasmosis bovina es una enfermedad causada por la bacteria Gram-negativa Anaplasma marginale, afecta mayormente a ganado en pastoreo de las zonas tropicales en donde se concentran las mayores poblaciones de bovinos en explotaciones extensivas en México. La enfermedad puede ocasionar hasta $25 \%$ de las pérdidas totales por muerte de animales que se movilizan al trópico para programas de mejoramiento genético ${ }^{(26)}$. La forma clínica se manifiesta por anemia, ictericia, inapetencia, pérdida de peso y producción láctea, aborto en el tercer tercio y muerte. En el INIFAP, la Unidad de Anaplasmosis fue fundada por el Dr. Ramón Aboytes Torres en 1994, ahí se realizan investigaciones sobre 
diagnóstico, epidemiología, respuesta inmune del bovino, cultivo in vitro de la bacteria y la generación de vacunas.

\section{Aportes del INIFAP}

Diagnóstico y epidemiología. Se han efectuado estudios serológicos y moleculares de las que se estimaron tasas de prevalencia del $50 \%$ en el norte de Veracruz ${ }^{(27)}$. El diagnóstico serológico se mejoró con el desarrollo de un ensayo inmuno enzimático indirecto en placa (ELISAi), el cual ha sido adoptado por el SENASICA ${ }^{(28)}$. En estudios de epidemiología molecular usando como marcadores a los genes mspl $\alpha$ y msp4, se ha observado que las cepas mexicanas poseen una distribución que permite suponer su migración. También se encontró que varias cepas de A. marginale presentes en México, son más parecidas a las caracterizadas en Brasil que a cepas de los EE.UU. ${ }^{(29)}$. En el laboratorio se tienen resguardadas más de 20 cepas, las que han sido recolectadas en diferentes estados de la República, mismas que se han usado para la comprobación de antígenos conservados ${ }^{(30,31)}$. Inmunidad y vacunas contra la anaplasmosis. A. marginale infecta eritrocitos maduros lo que hace que se comporte como una bacteria extracelular, ya que no infecta células nucleadas por lo que no induce una respuesta típica tipo Tc con células $\mathrm{CD}^{+}$, y se presenta una respuesta Th1. Ese modelo de respuesta inmune tipo Th1 había sido previamente postulado $^{(32)}$; en el INIFAP fue ensayado en terneras en las que normalmente se establece la infección pero resisten la presentación clínica de la enfermedad. El modelo también fue corroborado en bovinos adultos, en los que se observó una respuesta de tipo Th1, asociada a la presencia de IgG2, Interferón- $\gamma$ y linfocitos T cooperadores (Th) $\mathrm{CD}^{+}$, lo cual, es esencial para la resistencia a la presentación clínica de la anaplasmosis ${ }^{(33)}$.

Se desarrolló un inmunógeno inactivado con el que se logró inducir inmunidad protectora a un desafío homólogo ${ }^{(28,34,35)}$. Buscando alternativas de amplio espectro, se identificó una cepa de A. marginale del estado de Yucatán, a la que se le denominó “Tizimín” y se caracterizó como cepa de baja virulencia natural ${ }^{(36)}$. Esa cepa se utilizó como vacuna y se demostró que protegió ante un desafío heterólogo en bovinos vacunados con dosis de $1 \times 10^{4}-1 \times 10^{10(37)}$. Con el inmunógeno inactivado se han vacunado animales tanto locales como de importación en Veracruz y Tamaulipas; de esa manera se ha contribuido para reducir la morbilidad y mortalidad por anaplasmosis. Por otra parte, el uso del inmunógeno vivo se ha limitado debido a la dificultad de su mantenimiento en nitrógeno líquido.

En México se sabe que el vector biológico más importante de A. marginale son las garrapatas Rhipicephalus microplus ${ }^{(38,39)}$. En los laboratorios del propio INIFAP se demostró la transmisión trans-ovárica, lo que se logró con larvas de $R$. microplus que fueron alimentadas sobre bovinos infectados, las que posteriormente transmitieron la infección a bovinos susceptibles ${ }^{(40)}$. 
Estudios del genoma. La publicación del primer genoma completo de A. marginale fue en $2005^{(41)}$. Lo que revolucionó el estudio de los candidatos potenciales para vacunas de esta bacteria; actualmente existen 23 secuencias completas, incluyendo a siete cepas mexicanas $^{(42,43)}$. Para el desarrollo de inmunógenos se han analizado proteínas de membrana con potencial vacunal ${ }^{(44)}$, y se han realizado ensayos con proteínas recombinantes o péptidos sintéticos ${ }^{(31)}$. Sin embargo, todavía no existe un inmunógeno capaz de proteger de manera total a bovinos desafiados experimental o naturalmente contra esta bacteria. Actualmente, en la Unidad de Anaplasmosis los estudios están enfocados en dichas secuencias, para que en el diseño de vacunas se incluyan proteínas asociadas a vías de transporte, señalización o metabólicas ${ }^{(30)}$.

Perspectivas. Con la publicación de los 23 genomas de A. marginale, las secuencias se deben analizar mediante procedimientos de bioinformática. De modo que se establezcan criterios para la identificación de candidatos vacunales, ligados a funciones vitales o de virulencia. Actualmente, existen ejemplos de vacunas multiepitópicas y estrategias de vacunología reversa; por lo que el grupo de investigación está haciendo uso de esas herramientas para diseñar nuevas vacunas contra $A$. marginale ${ }^{(30)}$. Es muy probable que se identifiquen proteínas diferentes a las ya estudiadas para incluirlas en una vacuna. Lo cual, puede ocurrir en un periodo no mayor de cinco años, para entonces disponer de un inmunógeno que se use de manera amplia y segura.

\section{Brucelosis}

La brucelosis es una enfermedad infecciosa causada por bacterias del género Brucella que afecta a diferentes especies domésticas como los bovinos, ovinos y caprinos. La especie más importante que afecta al ganado bovino es Brucella abortus ${ }^{(45)}$. En México la brucelosis es la principal zoonosis de origen bacteriano. En los bovinos los signos clínicos más notorios son de tipo reproductivo, incluyen aborto y reducción en la producción láctea, por lo que tiene alto impacto en la ganadería bovina. Para el control de la enfermedad en el país existe la Campaña Nacional contra la Brucelosis en los animales, en la que se aplica la norma NOM-041-ZOO-1995 basada en el diagnóstico y la vacunación.

A nivel nacional para la inmunización del ganado bovino se usan las cepas S19 y RB51 ambas de B. abortus. La S19 induce la presencia de anticuerpos en el suero y en la leche, pero interfiere con las pruebas diagnósticas oficiales; por lo que la alternativa es la RB51 ${ }^{(46-49)}$. Para el diagnóstico los métodos serológicos más utilizados son la prueba de tarjeta al $8 \%$ y la de rivanol ${ }^{(50)}$; estas pruebas detectan anticuerpos contra los componentes de la membrana externa de Brucella, dirigidos contra la cadena $\mathrm{O}$ del lipopolisacárido (LPS) que es la estructura más antigénica de las cepas lisas ${ }^{(51)}$. 
A pesar de los esfuerzos realizados en la campaña, la brucelosis en México continúa con un efecto desfavorable en la salud animal y humana. La prevalencia en las unidades de producción es superior al $20 \%$; en humanos cada año en promedio se reportan 3,000 casos nuevos (Secretaria de Salud, CENAPRECE 2013-2018).

\section{Aportes del INIFAP}

En el INIFAP los investigadores han hecho contribuciones relevantes a la campaña en múltiples aspectos. Las pruebas diagnósticas que se aplican de manera directa o indirecta han sido producto de sus investigaciones, y son avaladas por la Norma Oficial Mexicana. Las pruebas que se utilizan son la de rosa de bengala, rivanol, fijación de complemento y anillo en leche. No obstante, con el uso de esas pruebas se dificulta diferenciar entre animales vacunados e infectados, especialmente en los que son revacunados; lo cual, se ha solventado con la prueba de inmunodifusión radial (IDR) ${ }^{(52)}$. Esa prueba a su vez facilitó el desarrollo de otras con mayor sensibilidad y especificidad, como la ELISA y la fluorescencia polarizada, en las que se utiliza como antígeno el polisacárido denominado hapteno nativo $(\mathrm{HN})^{(49,53)}$.

En relación a la patogenia de la brucelosis, se estudió la sobrevivencia y tráfico intracelular de la cepa vacunal RB51 vs cepas de campo en células fagocíticas. De esa manera se observó menor tiempo de sobrevivencia de la cepa vacunal y se infirió una menor probabilidad de causar enfermedad ${ }^{(54)}$.

Para demostrar la efectividad de las vacunas que se usan en la campaña se ha evaluado el efecto de la revacunación y el manejo de hatos infectados. También se han realizado ensayos con vacunas de nueva generación como las mutantes $r f b K^{(47,55,56)}$. Con la vacuna RB51 se expuso el riesgo potencial para la salud pública, debido a que se demostró su eliminación en leche y en secreciones vaginales de las vacas ${ }^{(57)}$. Si bien la cepa vacunal RB51 desplazó a la Cepa19, aún se desconoce su potencial protector real; aunque se ha demostrado su eficacia en la eliminación de animales reactores a las pruebas convencionales. La vacunación per se no ha sido suficiente para reducir la alta incidencia en hatos infectados ${ }^{(46,47)}$. La vacunación con la cepa RB51 se ha descrito que no interfiere con las pruebas de diagnóstico oficiales por carecer de la cadena "O". Si bien se han observado algunas respuestas "atípicas" positivas, estas se han atribuido a contacto con cepas de campo ocurridas durante los estudios ${ }^{(58,59)}$. Al usar como vacunas las mutantes rugosas RB51 y la $r f b K$ se ha descrito la inducción de una protección adecuada en un hato en condiciones de prevalencia media ${ }^{(56)}$.

Perspectivas. A pesar de la existencia de la campaña nacional para el control de la brucelosis se mantiene un nivel de prevalencia e incidencia que conlleva repercusiones económicas y sociales. Por lo que la prevención y control de la brucelosis podría plantearse 
bajo el concepto de "Una Salud"; así se involucraría a los productores y a las autoridades encargadas de la salud animal y salud humana. Técnicamente se deben continuar proyectos que permitan mejorar la eficacia y seguridad de las vacunas existentes y, desarrollar nuevos tipos de vacunas.

\section{Tuberculosis}

La tuberculosis bovina es una enfermedad crónica causada por la micobacteria Mycobacterium bovis que pertenece al complejo de Mycobacterium tuberculosis. M. bovis afecta a una gran variedad de especies incluyendo al humano. En México la tuberculosis es la segunda zoonosis de origen bacteriano más importante después de la brucelosis ${ }^{(60)}$. El control depende de la aplicación de la Norma Oficial Mexicana NOM-031-ZOO-1995 de la Campaña Nacional Contra la Tuberculosis Bovina (Mycobacterium bovis) ${ }^{(61)}$, cuya estrategia se basa en el diagnóstico y la eliminación de reactores. Para el diagnóstico se realiza la prueba de la tuberculina, utilizando como antígeno el derivado proteico purificado bovino (PPD) elaborado con M. bovis de la cepa AN5. El PPD bovino se aplica en el pliegue caudal o bien a la par con el PPD aviar elaborado con $M$. avium cepa D4, en una prueba cervical comparativa ${ }^{(62)}$. Los animales positivos a esta prueba son enviados al rastro, el diagnóstico se confirma por análisis bacteriológico específico y por histopatología de lesiones granulomatosas, lo que está establecido en la NOM-031-ZOO-1995 ${ }^{(61)}$. En nuestro país la prevalencia usualmente superior al $2.5 \%$ en las unidades de producción de leche, en ganado productor de carne es inferior, pero en ambos sistemas afecta la comercialización del ganado. En humanos cada año se reportan más de 15,000 casos nuevos de tuberculosis (Secretaria de Salud, CENAPRECE 2017).

\section{Aportes del INIFAP}

El INIFAP a través de sus investigadores ha contribuido en el desarrollo y aplicación de las diferentes técnicas de diagnóstico que se aplican en la campaña, las cuales son avaladas por la Norma Oficial Mexicana. Destaca el estudio que demostró que animales en las fases terminales de la tuberculosis no se pueden identificar con la prueba de la tuberculina. Por lo que se instrumentaron pruebas complementarias como ELISA, Interferón- $\gamma$ y spoligotyping con las que se mejoró la confiabilidad del diagnóstico y, se logró identificar a esos animales anérgicos ${ }^{(62)}$.

Para el aislamiento de micobacterias se estableció como rutina el uso del tetraborato de sodio para la conservación óptima de muestras hasta por 90 días, esa también es una contribución de investigadores del INIFAP. Otro aporte fue el uso de la PCR y del análisis histopatológico con tinción de Ziehl-Neelsen, con lo que se mejoró la sensibilidad y especificidad sobre el cultivo bacteriológico ${ }^{(63)}$. Un logro a destacar fue el desarrollo de la 
PCR de punto final y de la PCR-multiplex, pruebas con las que es posible diferenciar entre animales vacunados con BCG e infectados con cepas de campo ${ }^{(64,65)}$.

En México no existe ninguna vacuna autorizada para prevenir la tuberculosis en animales; no obstante, en el INIFAP se han realizado estudios de la vacuna BCG utilizada en humanos, para evaluar su capacidad protectora en animales. Se han utilizado animales de laboratorio como modelo y se han realizado ensayos preliminares en bovinos. En un estudio con becerras vacunadas con BCG y desafiadas con una cepa patógena de $M$. bovis, se demostró una marcada reducción de lesiones granulomatosas. Por lo que se ha sugerido su uso para el control de la tuberculosis en zonas de alta prevalencia ${ }^{(66)}$.

Perspectivas. La información científica que se ha generado, asociado a la existencia de una campaña para el control de la tuberculosis con una Norma Oficial presume la factibilidad de un control eficiente de la tuberculosis bovina. Sin embargo, se debe demostrar sólidamente la conveniencia del uso de la vacuna BCG, que es actualmente la única posible vacuna para prevenir la tuberculosis en el ganado bovino. Al mismo tiempo, se debe establecer una línea de investigación alterna para otra vacuna que no interfiera con la discriminación entre animales vacunados e infectados. Lo que implicaría una reducción de la prevalencia y un control eficiente de la tuberculosis bovina.

\section{Paratuberculosis}

La paratuberculosis es una enfermedad infectocontagiosa crónica que afecta al ganado bovino, ovino y caprino. Es causada por Mycobacterium avium subespecie paratuberculosis (Map); se caracteriza por producir lesiones de tipo granulomatoso en intestino delgado. Ocasiona el síndrome de mala absorción de los nutrientes, los animales infectados pierden su condición corporal y disminuye la capacidad productiva. El agente etiológico es eliminado en las heces, por lo que los animales se infectan al ingerir calostro, leche, alimento o agua contaminados. La propagación lenta de la enfermedad y su curso crónico ocasionan pérdidas económicas periódicas ${ }^{(67)}$.

\section{Aportes del INIFAP}

Investigadores del entonces CENID-Microbiología obtuvieron un antígeno protoplásmico de una cepa denominada Map 3065 derivada de un caso clínico de un ovino. Ese antígeno se usó para estandarizar las técnicas de inmunodifusión en agar (IDGA) y el ensayo inmuno-enzimático (ELISA) ${ }^{(68)}$.

En México se han determinado indicadores epidemiológicos en unidades de producción (UP) de los estados de Chihuahua, Coahuila, Sinaloa, Durango, San Luis Potosí, Jalisco, 
Aguascalientes, Guanajuato, Querétaro, Hidalgo, Puebla, Chiapas y Veracruz. Las prevalencias variaron de 1.0 a $32.37 \%$ en los diferentes estados; al considerar a cada UP las prevalencias variaron de 1.0 a $88.87 \%$. En otro estudio epidemiológico la presencia de la paratuberculosis se asoció a las condiciones sanitarias de cada UP, lo cual, permitió emitir recomendaciones del manejo sanitario del para el control de la enfermedad ${ }^{(67,69,70,71)}$. Otra técnica que se instrumentó fue la fluorescencia polarizada (FPA), con la que se mejoraron las tasas de sensibilidad y especificidad epidemiológicas ${ }^{(72)}$. También se implementó una PCR, en la que la extracción del ADN se hace a partir de las heces, leche, quesos, o tejidos con lesiones. Usando esa técnica se confirman casos de animales negativos en serología; los cuales en caso de permanecer en el hato serían la principal fuente de infección. Así es que la PCR resulta útil como prueba confirmatoria de la enfermedad.

Adicionalmente se ha estandarizado una PCR en formato anidado (PCRa), para la que se diseñaron iniciadores que amplifican una región del gen de la secuencia de inserción 900 específica de Map. Con la PCRa los resultados se consiguen en un tiempo más corto y se obtiene alta sensibilidad y especificidad. Se debe contrastar que con el aislamiento bacteriológico regularmente se requieren 16 semanas $^{(73)}$.

Perspectivas. Para entender los procesos de la inmunidad humoral y celular del bovino hacia $M$. avium subespecie paratuberculosis, se requiere generar una línea de investigación, y el reto será desarrollar un inmunógeno efectivo para la prevención de la enfermedad.

\section{Enfermedad respiratoria de los bovinos}

Es una enfermedad multifactorial que involucra la exposición a agentes virales, bacterianos, factores del ambiente y fisiológicos que estresen a los bovinos. Se ha descrito que es la enfermedad más común y costosa que afecta al ganado bovino en el mundo. Clínicamente se manifiesta fiebre $\left(>40{ }^{\circ} \mathrm{C}\right)$, secreción nasal y ocular, disnea, inapetencia, depresión, postración y muerte. El impacto económico es cuantioso debido a la morbilidad, mortalidad, costos de los tratamientos y baja en la producción.

En la enfermedad respiratoria de los bovinos (ERB) participan los virus de la rinotraqueitis infecciosa bovina (IBR), el respiratorio sincitial bovino (VRSB), el de diarrea viral bovina (DVB), el de parainfluenza-3( $\left.\mathrm{PI}_{3}\right)$ y el herpes virus bovino tipo 1. Los virus crean las condiciones propicias para la colonización y replicación de las bacterias, facilitando su adhesión en las células infectadas. De esta manera en bovinos con infecciones virales y sometidos a condiciones de estrés, se presentan infecciones respiratorias severas asociadas a bacterias. Las más frecuentes son Mannheimia haemolytica, Pasteurella multocida e Histophilus somni, estas normalmente son parte de la microbiota del tracto respiratorio alto. 
Poseen diversos factores de virulencia, $M$. haemolytica produce una leucotoxina que afecta a leucocitos de rumiantes; $P$. multocida tiene una cápsula antifagocítica y lipopolisacáridos; H. somni puede sobrevivir intracelularmente y es capaz de producir biopelícula ${ }^{(74)}$. El complejo es capaz de alterar las funciones de los macrófagos alveolares, se suprime la proliferación de los linfocitos, se induce apoptosis, se modifican la expresión de citocinas y se provoca un proceso inflamatorio ${ }^{(75)}$.

\section{Aportes del INIFAP}

Se desarrolló un proyecto colaborativo entre el entonces CENID-Microbiología del INIFAP y la UNAM denominado "Complejo Neumónico en Rumiantes", cuyo objetivo fue determinar los géneros bacterianos participantes en la ERB, sus serotipos y resistencia a los quimioterapéuticos. Así se logró el aislamiento de H. somnus $\left(H\right.$. somni) ${ }^{(76)}$, P. haemolytica (M. haemolytica) y P. multocida. También se hizo la serotipificación y la caracterizaron de su resistencia a productos quimioterapéuticos. Asimismo, se encontró que la mayoría de los serotipos de $M$. haemolytica pertenecían al tipo A1 y los de $P$. multocida al tipo $\mathrm{A}^{(77,78,79)}$; concretamente se detectó resistencia a la penicilina, ampicilina y estreptomicina ${ }^{(80,81)}$. Posteriormente, se evidenciaron factores de virulencia como la leucotoxina en $M$. haemolytica $^{(82)}$ y la formación de biopelícula en $P$. multocida, M. haemolytica y $H$. somni ${ }^{(83)}$. Además se observó que $P$. multocida produce vesículas en la membrana externa $^{(84)}$.

De los aislados se generaron cepas con las que se logró formular una bacterina-toxoide para la prevención de la ERB, el cual fue evaluado en ovinos como modelo ${ }^{(85,86,87)}$. El biológico generado es actualmente producido en el INIFAP y se usa en algunos programas sanitarios de ovinos.

Perspectivas. La prioridad será desarrollar biológicos con cepas nacionales de virus IBR, VRSB y $\mathrm{PI}_{3}$, y combinarlas con cepas vivas atenuadas o subunidades de $M$. haemolytica, $P$. multocida y H. somni para conferir protección efectiva contra la ERB. Para mejorar el diagnóstico será necesario iniciar estudios de metabolómica, así se podrá monitorear los metabolitos durante el curso de la enfermedad. También sería deseable crear una línea de investigación sobre la resistencia genética de los bovinos a la ERB. Colateralmente, la transcritómica sería una herramienta muy útil para tratar de hacer una selección genética y conformar hatos resistentes a la ERB.

\section{Leptospirosis}

La leptospirosis es una zoonosis de distribución mundial, es causada por bacterias del género Leptospira. Con base en el análisis de ADN éste género incluye a 22 especies 10 
patógenas, 5 intermedias y 7 saprófitas $^{(88)}$. Por serología se reconocen más de 300 serovariedades ${ }^{(89)}$. A nivel mundial hardjo es la serovariedad más comúnmente detectada en bovinos ${ }^{(90)}$. Los pequeños mamíferos son los reservorios más importantes de la bacteria, los grandes herbívoros son fuente de infección, el humano puede ser hospedador accidental $^{(91)}$.

Los bovinos son portadores renales de la Leptospira spp. por lo que eliminan a la bacteria por la orina y contaminan el medio ambiente ${ }^{(92)}$. La leptospirosis ocasiona trastornos reproductivos tales como abortos, mortinatos, becerros prematuros débiles y una reducción de la producción láctea; lo que implica pérdidas económicas considerables ${ }^{(93)}$. En México las primeras descripciones de leptospirosis se hicieron en 1928 y 1930 en humanos y en bovinos, respectivamente ${ }^{(94)}$.

\section{Aportes del INIFAP}

En un trabajo colaborativo entre INIFAP, UAM y UAEM se reportó la situación de la leptospirosis bovina en México. Se determinaron tasas de prevalencia en diferentes zonas ecológicas del país; en la árida y semiárida la prevalencia fue $37.8 \%$; en el trópico seco $45.9 \%$; en trópico húmedo $63.8 \%$ y en la zona templada $39.4 \%$. En todas las regiones se demostró la presencia de las serovariedades hardjo, wolffi y tarassovi. En la región templada se detectaron las serovariedades icterohaemorrhagiae, portland-Vere, bratislava, pyrogenes, canicola y pomona ${ }^{(95)}$. Se aislaron las serovariedades grippotyphosa, mini y tarassovi, lo que no se había realizado en México ${ }^{(96,97)}$. En otros estudios epidemiológicos fueron identificadas las mismas serovariedades, pero las prevalencias tuvieron una amplia variación de 31 a $91 \%{ }^{(98-103)}$.

Para el diagnóstico, en el INIFAP se instrumentó la técnica de la PCR que permitió la detección de bacterias en la orina recolectada de bovinos con antecedentes de problemas reproductivos $^{(100)}$.

Para la prevención de la enfermedad se generaron bacterinas, una adicionada con adyuvante usando vitaminas liposolubles, con la que se obtuvieron resultados satisfactorios ${ }^{(104)}$. Otra bacterina se elaboró con serovariedades aisladas en el estado de Chiapas, las cuales no estaban contenidas en las bacterinas comerciales; con ese biológico homólogo se observó excelente nivel de protección en bovinos susceptibles. Actualmente en el INIFAP se dispone de una bacterina que ha sido validada en hatos de animales de lechería familiar ${ }^{(105)}$.

Perspectivas. Es evidente la endemicidad y alta prevalencia de la leptospirosis en México, por lo que es un verdadero reto masificar el uso de la microaglutinación que es la prueba de referencia. Para determinar las serovariedades de Leptospira presentes en las diferentes regiones, y entonces elaborar bacterinas homólogas que prevengan efectivamente la 
leptospirosis. Se debe generar una línea de investigación sobre el desarrollo de vacunas de tipo molecular que se puedan usar en cualquier región ecológica. También, sería recomendable instrumentar alguna metodología precisa con alta sensibilidad y especificidad, rápida en su ejecución y de bajo costo. Lo cual puede redundar en un mejor diagnostico que incrementará parámetros reproductivos y productivos del ganado bovino.

\section{Garrapatas}

Las garrapatas son ectoparásitos hematófagos capaces inyectar toxinas y de transmitir diferentes patógenos como A. marginale y Babesia spp. con altas tasas de morbilidad y mortalidad en el ganado. De la diversidad de garrapatas identificadas en México la más importante es Rhipicephalus microplus. Actualmente son un problema global por su gran adaptabilidad a diferentes nichos ecológicos, se considera que el $65 \%$ del territorio nacional está infestado con esa garrapata.

\section{Aportes del INIFAP}

Epidemiología. En un estudio epidemiológico que comprendió diferentes estados del país, se corroboró que la distribución de $R$. microplus se asoció esencialmente a la temperatura ambiental, lluvia y vapor de agua ${ }^{(106)}$. En otra investigación se observó mayor eficiencia y aptitud reproductiva de garrapatas de una cepa nativa recolectada en campo en Sinaloa, comparada con una cepa de referencia del CENID-SAI ${ }^{(107)}$.

Control biológico. Para el control de garrapatas esta estrategia ha sido bien documentada en estudios realizados en el INIFAP. De la evaluación de técnicas para la recolección de larvas de garrapatas $R$. microplus, la de bandera con doble recorrido fue seleccionada para diferentes estudios. Se evaluó el efecto de la recuperación de larvas $R$. microplus usando leguminosas tropicales en el estado de Morelos ${ }^{(108)}$. En otro estudio se evaluó el efecto antilarvas usando los pastos Stylosanthes humilis, S. hamata, Cenchurus ciliaris y Andropogon gayanus en parcelas infestadas artificialmente. Del cual se observó efecto favorable en las parcelas de $S$. humilis en las que se recuperó solo $3 \%$ de larvas vivas ${ }^{(109)}$. En otra investigación usando plantas maduras de $S$. humilis y $S$. hamata no hubo ningún efecto anti-garrapata $^{(110)}$. Por otra parte, al evaluar a las leguminosas Leucaena leucocephala, Macroptilium artropurpureum, S. humilis y S. hamata se notó importante reducción de larvas de $R$. microplus ${ }^{(111)}$. Con base en estos hallazgos, se identificaron algunos compuestos químicos en $S$. humilis y $S$. hamata como posibles causantes del efecto repelente ${ }^{(112)}$. Asimismo, en otro estudio usando el pasto gordura M. minutiflora también se observó reducción en la recuperación de larvas ${ }^{(113)}$. 
Otras estrategias han involucrado el uso de hongos o bacterias para el control de las garrapatas; así al utilizar al hongo entomopatógeno Metarhizium anisopliae se demostró su capacidad para infectar a las garrapatas y de inducir hasta $100 \%$ de mortalidad, lo que permitió inferir que puede ser un acaricida potencial para el control biológico de $R$. microplus $^{(114)}$. Por otra parte, en garrapatas adultas ingurgitadas que se infectaron experimentalmente con la bacteria Staphylococcus saprophyticus, se logró inducir mortalidad de las garrapatas ${ }^{(115)}$.

Se reportó por primera vez que el hongo Aspergillus flavus es capaz de infectar al $80 \%$ de garrapatas adultas ingurgitadas, a las masas ovígeras y a las larvas que emergen después de la incubación, en condiciones controladas ${ }^{(116)}$.

Resistencia. Este es uno de los tópicos más estudiados en el INIFAP; en uno de los primeros estudios se demostró que en poblaciones de garrapatas $R$. microplus resistentes a organofosforados, hay una elevada expresión de enzimas carboxilesterasas ${ }^{(117)}$. Posteriormente, se caracterizaron algunos genes que codifican para esterasas, cuya utilidad era disponer de marcadores moleculares para discriminar cepas de garrapatas susceptibles y resistentes a ixodicidas ${ }^{(118)}$. Se analizaron genes que codifican para carboxilesterasas B mediante ensayos de la PCR en larvas individuales de $R$. microplus, con lo que se detectaron polimorfismos al hacer la traducción a proteína ${ }^{(119,120)}$, además se identificó una esterasa en la cepa “Coatzacoalcos" (Cz EST9) ${ }^{(121)}$.

En otra investigación se trató de identificar la asociación de mutaciones de genes con resistencia a los piretroides. Notándose que la presencia de la mutación no se asocia con la resistencia en la forma dosis-respuesta ${ }^{(122)}$. En estudios referentes a la resistencia a piretroides, trataron de correlacionar diferentes pruebas diagnósticas, y se concluyó que la resistencia está mediada por una mutación en el gen blanco $k d r^{(123)}$. Adicionalmente se ha estudiado sobre la participación del citocromo P450, y se ha observado que se expresa en altos niveles en cepas resistentes a piretroides ${ }^{(124)}$. Pero se ha evidenciado un proceso multifactorial en la resistencia de $R$. microplus a los organofosforados y a los piretroides $^{(125)}$. Se reportó el primer caso de resistencia al amitraz ${ }^{(126)}$ y se describió que la presión de selección con amitraz incrementaba el nivel de resistencia en poblaciones de campo $^{(127)}$. Adicionalmente se instrumentó la metodología de la RT-PCR para medir la expresión de colinesterasa y carboxilesterasa en garrapatas resistentes a acaricidas ${ }^{(128)}$.

Control inmunológico. Para el control de garrapatas, se han identificado proteínas inmunogénicas derivadas de extractos de los ovarios de $R$. microplus obtenidas de bovinos después de su inmunización ${ }^{(129)}$. En otros estudios se ha caracterizado y evaluado la homología de las proteínas vitelogenina ${ }^{(130)}$ y ATAQ, ambos como posibles candidatos vacunales contra $R$. microplus ${ }^{(131,132)}$. Algunos experimentos de inmunización contra garrapatas $R$. microplus y $R$. annulatus han mostrado resultados no concluyentes. No 
obstante, se han continuado estudios similares; tales como el uso de la proteína subolesina, que se describió como un blanco potencial para desarrollar una vacuna contra las garrapatas $^{(133,134)}$.

Perspectivas. Es innegable la necesidad de hacer mayor énfasis en la investigación de la epidemiología de las garrapatas; especialmente el cambio climático es un factor que está favoreciendo su mayor distribución espacial y, por ende la infestación de ganado no previamente expuesto. También es imperativo desarrollar técnicas moleculares para el diagnóstico rápido de resistencia a los diferentes principios químicos de los ixodicidas. Colateralmente se debe mantener una línea de investigación del control biológico que involucre la identificación y caracterización de plantas. Debe ser prioritaria una línea de investigación sobre el desarrollo de inmunógenos a partir de proteínas conservadas, asociadas a funciones vitales de las garrapatas. El reto mayor será instrumentar un programa de control integrado para el control de $R$. microplus.

\section{Babesiosis}

La babesiosis bovina o piroplasmosis es una enfermedad parasitaria causada por protozoarios del genero Babesia que invaden a los eritrocitos del hospedador bovino. En México las especies reconocidas son Babesia bovis y B. bigemina, ambas son transmitidas por garrapatas $R$. microplus y $R$. annulatus ${ }^{(135)}$. Del inventario ganadero de país que es de $35 ’ 224,960$ cabezas $^{(136)}$, aproximadamente el $70 \%$ se mantiene con exposición permanente a la infestación por garrapatas. Por lo que la prevalencia de Babesia spp. varía entre 50 y $96 \%$, lo que a su vez explica el alto riesgo de la ocurrencia de brotes ${ }^{(137)}$.

Se ha señalado que la babesiosis es la enfermedad más importante transmitida por artrópodos al ganado bovino ${ }^{(138)}$. En nuestro país se estiman pérdidas por 573.61 millones de dólares anuales por las garrapatas y enfermedades que transmiten ${ }^{(139)}$. No obstante, no existe ninguna vacuna comercial, ni la producción de reactivos diagnósticos nacionales. Aunado a lo antes citado, la amplia distribución de resistencia a los ixodicidas y el cambio climático, son factores preponderantes que contribuyen a la abundancia de vectores y a la facilitación en la transmisión de patógenos ${ }^{(140)}$.

\section{Aportes del INIFAP}

Diagnóstico y epidemiología. En el INIFAP se han instrumentado métodos directos para el diagnóstico confirmatorio de babesiosis. Están disponibles rutinariamente técnicas para la identificación de los estadios intraeritrocíticos. El más común es el frotis de sangre periférica con el que se hace la identificación de B. bovis y B. bigemina mediante la observación microscópica; igualmente se elaboran improntas de tejido cerebral 
particularmente para la detección de $B$. bovis ${ }^{(141,142)}$. También se puede hacer el análisis histopatológico de tejidos recolectados a la necropsia ${ }^{(143,144,145)}$. Se han desarrollado métodos indirectos cuyo fundamento es inmunológico, con los que se detectan anticuerpos circulantes anti-B. bovis o anti-B. bigemina ${ }^{(143,146,147)}$. Para estos procedimientos se han obtenido antígenos parasitarios que han sido definidos y caracterizados ${ }^{(148,149)}$. Se han observado ventajas al compararlos con antígenos crudos con los que regularmente se obtiene una baja especificidad en las pruebas diagnósticas, esto ocurre por la similitud de epitopos presentes entre diferentes especies de Babesia ${ }^{(146,150,151)}$; además de que puede generar reacciones cruzadas con otras especies ${ }^{(148,151,152)}$.

En nuestro grupo de investigación también se ha mejorado la especificidad de las pruebas serológicas. Para lo cual se han clonado genes que codifican por péptidos inmunodominantes y específicos de especie; además se han usado anticuerpos monoclonales $^{(148,149,153)}$.

En otros estudios se han identificado los antígenos más conservados para B. bovis $^{(154-158)}$, los cuales se utilizaron para desarrollar pruebas de ELISA indirecta para ambas especies $^{(159,160)}$, que a su vez fueron herramientas para el seguimiento serológico de animales experimentalmente inmunizados ${ }^{(161,162,163)}$. Esas pruebas también se incorporaron en estudios seroepidemiológicos de hatos de bovinos localizados en diferentes zonas ganaderas del país ${ }^{(160,164)}$.

Por otra parte, hubo un notorio avance en el diagnóstico directo; se reportaron procedimientos moleculares que detectan material genético de los parásitos. Estos han incluido el uso de sondas de ácidos nucleicos o técnicas de amplificación del ácido nucleíco $^{(165,166)}$, las cuales se han usado en estudios epidemiológicos en diferentes regiones ganaderas del país ${ }^{(167)}$. Usando el ADN genómico de B. bigemina se desarrolló una PCR con alta sensibilidad analítica, para lo cual se hacía la hibridación del producto amplificado con una sonda de $\mathrm{ADN}$ no radiactiva ${ }^{(168,169)}$. También se instrumentó un formato múltiple para la detección simultánea de B. bovis y B. bigemina; a lo que se agregó el diagnóstico de $A$. marginale $^{(166,170,171)}$. Las sondas de ADN fueron utilizadas en estudios epidemiológicos en Yucatán, Tabasco y Campeche ${ }^{(172,173)}$. De igual forma se usaron para el monitoreo de bovinos inoculados con cepas vacunales de B. bovis y B. bigemina $^{(149,174)}$; así como en el monitoreo de animales susceptibles introducidos a zonas endémicas ${ }^{(175,176)}$. Esta misma metodología demostró su utilidad para la detección del ADN de patógeno en las garrapatas $^{(177)}$; así como para la identificación específica de B. bovis y B. bigemina en la garrapata R. microplus ${ }^{(178,179)}$.

Prevención. Hasta ahora la mejor estrategia de prevención de babesiosis en regiones endémicas es la inmunización con vacunas vivas atenuadas, las cuales pueden ser derivadas de subinoculación en becerros esplenectomizados, o del cultivo in vitro de B. bovis y $B$. 
bigemina $^{(180)}$. Con la aplicación de vacunas atenuadas en bovinos susceptibles, se ha demostrado la inducción de una respuesta inmune sólida ante confrontaciones con parásitos de alta virulencia ${ }^{(181,182)}$.

Investigadores del INIFAP han participado en el desarrollo y adaptación del cultivo in vitro y actualmente se dispone de cepas atenuadas de B. bovis y B. bigemina en México ${ }^{(183,184)}$. El desarrollo en México de la vacuna atenuada a partir del cultivo in vitro se puede reseñar mediante diferentes estudios. Entre los que se incluye la demostración de la baja virulencia de las clonas de parásitos cultivados in vitro que fueron inoculados en bovinos susceptibles ${ }^{(185)}$. Al usar el material como inmunógeno fresco, se determinó que la dosis adecuada son $1 \times 10^{7}$ eritrocitos infectados para B. bovis o B. bigemina ${ }^{(186,187)}$. En otro estudio se evidenció la necesidad de incluir ambas especies de Babesia para inducir protección exitosa contra la enfermedad ${ }^{(188)}$. Resultados similares se obtuvieron con la vacunación de bovinos ante un desafío natural en el trópico ${ }^{(189)}$. Posteriormente, se determinó que el material derivado del cultivo in vitro que se retiraba de la criopreservación en nitrógeno liquido $\left(-196{ }^{\circ} \mathrm{C}\right)$, requería incrementar la dosis a $1 \times 10^{8}$ eritrocitos infectados de cada especie, para así proteger a bovinos ante el desafío con parásitos virulentos ${ }^{(190)}$. También se evaluó el uso de la vacuna en ganado nativo mantenido en explotaciones de alta endemicidad e inestabilidad enzoótica, en donde también se demostró un excelente nivel de protección contra la babesiosis ${ }^{(191)}$. En otro estudio, la vacuna fue adicionada con Lactobacillus casei y fue evaluada ante un desafío natural; se observaron mayores niveles de IgG1 específicos contra B. bovis y B. bigemina; sin embargo, el nivel de protección fue análogo al de la vacuna sin la bacteria ${ }^{(192)}$.

El cultivo in vitro de B. bovis y B. bigemina es aparentemente una metodología sencilla; sin embargo, pocos los laboratorios en el mundo lo hacen exitosamente. Después de más de 30 años de haberse establecido en México, existía una baja eficiencia en la producción de biomasa. En los últimos años, el INIFAP se ha posicionado como institución líder a nivel internacional por innovaciones que se han integrado al cultivo in vitro de B. bovis y $B$. bigemina. Se ha logrado eliminar el suero de bovino del medio de cultivo, que se sustituyó por componentes vitales como la insulina, transferrina, selenito y putrescina. Por primera vez, se logró transferir el proceso a un biorreactor de perfusión, de esa manera se incrementó $300 \%$ el número de eritrocitos infectados. Lo cual, implicó la obtención de un elevado número de dosis vacunales comparado con el procedimiento tradicional ${ }^{(193,194,195)}$. El material derivado del biorreactor al ser evaluado como inmunógeno confirió en bovinos un nivel de protección superior al $80 \%$ en un desafío de campo ${ }^{(196)}$. Ese inmunógeno sin la presencia de proteínas del suero, se ha propuesto que puede inducir una respuesta con mayor especificidad inmunológica ${ }^{(197)}$. Al mismo tiempo, la incorporación del biorreactor ha generado una línea de investigación sobre el uso de antígenos solubles derivados del sobrenadante del cultivo. Recientemente, el laboratorio del INIFAP se ha logrado por primera vez la proliferación de B. bigemina en medio de cultivo libre de componentes de 
origen animal, y también se transfirió exitosamente al biorreactor. Esto último representa un escalamiento del proceso para la producción de vacuna ${ }^{(198)}$. Esos cambios facilitarán la continuidad al desarrollo de vacunas subunitarias ${ }^{(199)}$. Las innovaciones antes descritas por su grado de invención han generado dos patentes otorgadas a favor del INIFAP y una más en trámite. Una denominada "Composición del cultivo in vitro libre de suero para la obtención de eritrocitos parasitados con Babesia spp." (Patente 347729). La otra denominada "Proceso para la elaboración de reactivo vacunal de eritrocitos parasitados con Babesia bovis o Babesia bigemina" (Patente 337161).

Perspectivas. Se requiere generar pruebas diagnósticas altamente sensibles con capacidad para identificar cepas de Babesia resistentes o susceptibles a los compuestos antibabesiales. También sería relevante instrumentar un procedimiento para discriminar cepas atenuadas (vacunales, convencionales, genéticamente modificadas) o virulentas de campo. Es indispensable un mapeo dinámico de la distribución y frecuencia para hacer la aplicación oportuna de procedimientos de prevención o control de la babesiosis. Las vacunas vivas ahora son la única forma de prevenir a la enfermedad, pero es imprescindible mantener a las ciencias ómicas para generar mayor conocimiento de las interacciones entre los parásitos y los bovinos. Ese conocimiento facilitará la conducción de vacunas subunitarias que pueden resultar más seguras y más fácilmente escalables.

\section{Conclusiones}

En el INIFAP se han desarrollado y adaptado herramientas diagnósticas de tipo serológico y molecular, que han contribuido en programas de prevención y control de las enfermedades del ganado bovino. También se han instrumentado técnicas para la detección de resistencia a los ixodicidas. Se ha determinado la distribución y frecuencia de algunas de las enfermedades más importantes que afectan la ganadería bovina en México. Los biológicos desarrollados comprenden vacunas contra la rabia, anaplasmosis y babesiosis; también una bacterina contra leptospirosis y una bacterina-toxoide contra neumonías. Además, ha se estudiado una vacuna con BCG contra tuberculosis y una vacuna de nueva generación contra la brucelosis. La perspectiva de la salud animal en enfermedades zoonóticas como la tuberculosis y la brucelosis sugieren dirigir esfuerzos científicos y técnicos a su eliminación. Se deberán desarrollar investigaciones sobre el efecto del cambio climático especialmente en enfermedades transmitidas por vectores. En futuros estudios de los investigadores del INIFAP sobre las enfermedades de los bovinos se deberán inevitablemente abarcar estudios moleculares. A través de protocolos y métodos de las ciencias ómicas, como la genómica, epigenómica, transcriptómica, proteómica, metabolómica y otras ómicas derivadas. Actualmente es la forma más apropiada para comprender los mecanismos de enfermedad, de esa manera se logrará generar vacunas más efectivas y se podrán diseñar herramientas diagnósticas más precisas; mismas que serán 
fundamentales en programas de control integral. Probablemente el reto mayor será que la investigación en salud animal que se realice en el INIFAP, se incorpore al concepto de "Una Salud". La que se ha definido como un proceso colaborativo multisectorial y transdiciplinario a nivel local, regional, nacional y global, basado en la vinculación entre humanos, animales, plantas y medio ambiente ${ }^{(200)}$.

\section{Literatura citada:}

1. INEGI. Instituto Nacional de Estadística, Geografía e Informática. Encuesta Nacional Agropecuaria. 2019.

2. OIE. World Organisation for Animal Health. The economics of animal health: direct and indirect costs of animal disease outbreaks. Paris, France. 2016.

3. FAO. Food and Agriculture Organization. Animal production and health. Economical analysis of animal diseases. 2016.

4. Loza RE, Nadin DSA, Morales SE. Molecular and biological properties of rabies viruses circulating in Mexican skunks: focus on $\mathrm{P}$ protein. Rev Mex Cienc Pecu 2012;3(2):155-170.

5. SENASICA. Servicio Nacional de Sanidad, Inocuidad y Calidad Agroalimentaria. Indicadores de la Campaña Nacional para la prevención y control de la rabia en bovinos y especies ganaderas. 2020 .

6. Loza RE, Rojas AE, Banda RVM, Nadin DS, Cortez GB. Detection of multiple strains of rabies virus RNA using primers designed to target Mexican vampire bat variants. Epidemiol Infect 2005;133(5):927-934.

7. Rojas AE, Loza RE, Banda RVM, Hernández BE. Use of reverse transcriptionpolymerase chain reaction to determine the stability of rabies virus genome in brains kept at room temperature. J Vet Diagn Invest 2006;18(1):98-101.

8. Loza RE, Aguilar SA, Bahloul Ch, Pastoret PP, Tordo N. Discrimination between epidemiological cycles of rabies in Mexico. Archives of Med Res 1999;30(2):144-149.

9. De Mattos CC, de Mattos CA, Loza RE, Aguilar SA, Orciari LA, Smith JS. Molecular characterization of rabies virus isolates from Mexico: Implications for transmission dynamics and human risk. Am J Trop Med Hyg 1999;(61):587-597.

10. Loza RE, De Mattos CC, Aguilar S, De Mattos CA. Aislamiento y caracterización molecular de un virus rábico obtenido de un murciélago no hematófago en la Ciudad de México. Vet Méx 2000;31(2):147-152. 
11. Nadin DSA, Loza RE. The molecular epidemiology of rabies associated with chiropteran hosts in Mexico. Virus Res 2006;117(2):215-226.

12. Loza RE, Rojas AE, Lopez J, Olivera FMT, Gomez LM, Tapia PG. Induction of protective immune response to rabies virus in sheep after oral immunization with transgenic maize. Vaccine 2012;3 (37):5551-5556.

13. Weimersheimer RJE, Loza RE. Desarrollo de un nuevo método para inactivación mediante radiación gamma, para la vacuna antirrábica V-319 Acatlán. Av Cienc Vet 1991;6(1):70.

14. Weimersheimer RJE, Loza RE. Estabilidad de la vacuna antirrábica V-319 Acatlán inactivada con radiación gamma (Cobalto-60). Téc Pecu Méx 1994;32(1):43-46.

15. Weimersheimer RJE, Loza RE. Caducidad de una vacuna antirrábica inactivada con radiación gamma (Cobalto-60a). Téc Pecu Méx 1996;34(3):172-174.

16. Weimersheimer RJE, Loza RE. Alternativa para inactivar vacunas antirrábicas, usando radiación gamma (Co-60). Vet Méx 1999;30(4):313-316.

17. Perrin P, Jacob Y, Aguilar SA, Loza RE, Jallet C, Desmézières E, et al. Immunization with DNA vaccine induces protection against rabies virus. Vaccine 2000;18(5-6):479486.

18. Perea AI, Loza RE, Rojas AE, Olivera FT, De la Vara GL, Gómez LM. Expression of rabies virus nucleoprotein in plants at high-levels and evaluation of immune response in mice. Plant Cell Rep 2008;27(4):677-685.

19. Rojas AE, Loza RE, Olivera FMT, Gomez LMA. Expression of rabies virus G protein in carrots (Daucus carota). Transgenic Res 2009;18(6):911-919.

20. Escalera ZM, Zepeda MML, Loza RE, Rojas AE, Méndez OML, Arias CF, et al. The evolution of bat nucleic acid sensing Toll-like receptors. Mol Ecol 2015;24(23):5899909.

21. Zepeda MML, Xiong Z, Escalera ZM, Runge AK, Thézé J, Streicker D, et al. Hologenomic adaptations underlying the evolution of sanguivory in the common vampire bat. Nat Ecol Evol 2018;2(4):659-668.

22. Grisset GP, White BJ, Larson RL. Structured literature review of responses of cattle to viral and bacterial pathogens causing bovine respiratory disease complex. J Vet Intern Med 2015;29(3):770-780. 
23. Correa P, Brown LN, Bryner JH. Presencia de anticuerpos contra rinotraqueitis infecciosa, diarrea viral bovina, parainfluenza 3, brucelosis, leptospirosis, vibriosis y Haemophilus somnus en sueros de bovinos con problemas patológicos, reproductores y respiratorios. Téc Pecu Mex 1975;(29):26-33.

24. Gómez RN, Basurto AFJ, Verdugo RA, Bauermann FV, Ridpath JF. Genetic diversity of bovine viral diarrhea virus in cattle from Mexico. J Vet Diagn Invest 2017;29(3):362-365.

25. Milián SF, Hernández OR, Hernández AL, Alvarado IA, Díaz AE, Mejía EF, et al. Seroprevalence and risk factors for reproductive diseases in dairy cattle in Mexico. J Vet Med Anim Health 2016;8(8):89-98.

26. Rodríguez SD, García OMA, Jiménez ORJ, Vega MCA. Molecular epidemiology of bovine anaplasmosis with a particular focus in Mexico. Infect Genet Evol 2009;9:1092-1101.

27. Cossío BR, Rodríguez SD, García OMA, García TD, Aboytes TR. Bovine anaplasmosis prevalence in northern Veracruz State, Mexico. Prev Vet Med 1997;(32):165-170.

28. Rodríguez SD, García OMA, Hernández SG, Santos CN, Aboytes TR, Cantó AJ. Anaplasma marginale inactivated vaccine: dose titration against a homologous challenge. Comp Immunol Microbiol Infect Dis 2000;(23):239-252.

29. Jiménez OR., Vega MCA, Oviedo ON, Rojas REE, García OMA, Preciado TJF, et al. Diversidad genética de la región variable de los genes mspla y msp4 en cepas de Anaplasma marginale de México. Rev Mex Cienc Pecu 2012;3(3):373-387.

30. Rodríguez CSD, Quiroz CR, Aguilar DH, Vara PJE, Pescador PD, Amaro EI, et al. Immunoinformatic analysis to identify proteins to be used as potential targets to control bovine anaplasmosis. Int J Microbiol. 2020;2020:8882031.

31. Barrera MAI, Cossío BR, Gutiérrez PJA, Tello LAT, Preciado de la Torre JF, et al. Immunolocalization of Vir B11 protein in the Anaplasma marginale outer membrane and its reaction with bovine immune sera. Rev Mex Cienc Pecu 2018;9(4):769-791.

32. Brown WC, Zhu D, Shkap V, McGuire TC, Blouin EF, Kocan KM, et al. The repertoire of Anaplasma marginale antigens recognized by CD4(+) T-lymphocyte clones from protectively immunized cattle is diverse and includes major surface protein 2 (MSP-2) and MSP-3. Infect Immun 1998;66(11):5414-22. 
33. Barigye R, Garcia OM, Rojas RE, Rodriguez SD. Identification of IgG2 specific antigens in three Mexican strains of Anaplasma marginale. Ann NY Acad Sci 2004;1026:84-94.

34. Rodríguez CSD, García OMA, Cantó AGJ, Hernández SG, Santos CN, Aboytes TR. Ensayo de un inmunógeno experimental inactivado contra Anaplasma marginale. Tec Pecu Mex 1999;37(1):1-12.

35. Orozco VLE, Rodríguez SD, Cantó AG, López FR, Jiménez OR, García OM. Anaplasma marginale field challenge: protection by an inactivated immunogen that shares partial sequence of mspl $\alpha$ variable region with the challenge strain. Vaccine 2007;(25):519-525.

36. García OMA, Aboytes TR, Hernández SG, Cantó AJG, Rodríguez SD. Anaplasma marginale: Diferentes grados de virulencia en dos aislados mexicanos. Vet Méx 2000;31(2);157-160.

37. Rodríguez CSD, García OMA, Rojas REE, Cantó AGJ, Preciado TJF, Rosario C, et al. Anaplasma marginale Yucatan (Mexico) strain. Assessment of low virulence and potential use as a live vaccine. Annals NY Acad Sci. 2008;(1149):98-102.

38. Piercy PL. Transmission of anaplasmosis. Ann NY Acad Sci 1956;64:40-48.

39. Shimada MK, Yamamura MH, Kawasaki PM, Tamekuni K, Igarashi M, Vidotto O, et al. Detection of Anaplasma marginale DNA in larvae of Boophilus microplus ticks by polymerase chain reaction. Ann NY Acad Sci. 2004;(1026):95-102.

40. Amaro EI, García OMA, Preciado TJF, Rojas REE, Hernández OR, Alpírez MF, et al. Transmission of Anaplasma marginale by unfed Rhipicephalus microplus tick larvae under experimental conditions. Rev Mex Cienc Pecu 2020;11(1):116-131.

41. Brayton KA, Kappmeyer LS, Herndon DR, Dark MJ, Tibbals DL, Palmer GH, et al. Complete genome sequencing of Anaplasma marginale reveals that the surface is skewed to two superfamilies of outer membrane proteins. Proc Natl Acad Sci USA 2005;102(3):844-9.

42. Quiroz CRE, Amaro EI, Martínez OF, Rodríguez CSD, Dantán GE, Cobaxin CM, et al. Draft genome sequence of Anaplasma marginale strain Mex- 01-001-01, a mexican strain that causes bovine anaplasmosis. Microbiol Resour Announc. 2018;7(16):e01101-18.

43. Martínez OF, Quiroz CRE, Amaro EI, Dantán GE, Preciado Torre JF, Rodríguez CS. Whole-genome sequencing of Mexican strains of Anaplasma marginale an approach to the causal agent of bovine anaplasmosis. Int J Genomics 2020;2020:5902029. 
44. Dark MJ, Lundgren AM, Barbet AF. Determining the repertoire of immunodominant proteins via whole-genome amplification of intracellular pathogens. PLoS One. 2012;7(4):e36456.

45. Díaz AE. Epidemiología de la brucelosis causada por Brucella melitensis, B. suis y B. abortus en animales domésticos. Revue Scientifique et Technique 2013;32(1):43-51.

46. Herrera LE, Hernández AL, Díaz AE. Study of brucellosis incidence in a bovine dairy farm infected with Brucella abortus, where cattle was revaccinated with RB51. International J Dairy Sci 2007;2(1):50-57.

47. Herrera LE, Palomares RG, Díaz AE. Milk production increase in a dairy farm under a six-year brucellosis control program. Ann New York Acad of Sci 2008;(1149):296299.

48. Leal HM, Jaramillo ML, Hernández AL. Producción de interferón gamma en cultivos de sangre completa en respuesta a antígenos de Brucella abortus en bovinos vacunados con RB51. Téc Pecu Méx 2007;45(2):147-159.

49. Aparicio BA, Díaz AE, Hernández AL, Pérez GR, Alfonseca SE, Suárez GF. Evaluación serológica y bacteriológica de un hato bovino con brucelosis y revacunado con dosis reducida de Brucella abortus cepa 19. Téc Pecu Méx 2003;41(2):129-140.

50. Alton GG, Forsyth JRL. Brucellosis. Medical microbiology. INRA 2003;(28):512-525.

51. Muñoz PM, Marín CM, Monreal D, González D, Garin BB, Díaz R, Mainar JRC, Moriyón I, Blasco JM. Efficacy of several serological tests and antigens for diagnosis of bovine brucellosis in the presence of false-positive serological results due to Yersinia enterocolitica O:9. Clin Diagn Lab Immunol 2005;12(1):141-51.

52. Díaz AE, Marín C, Alonso UB, Aragón V, Pérez OS, et al. Evaluation of serological tests for diagnosis of Brucella melitensis infection of goats. J Clin Microbiol 1994;(32):1159-1165.

53. Ramirez PC, Díaz AE, Rodriguez PC, Morales LA, Alvarez OG, Gómez FR. Improved performance of Brucella melitensis native hapteno ver Brucella abortus OPS trace ron goat antibody detection by the fluorescence polarization assay. Vet Immun and Immunophatol 2008;123(3-4):223-229.

54. Arellano RB, Díaz AE, Leal HM, Hernandez L, Gorvel JP. Intracellular trafficking study of a RB51 B. abortus vaccinal strain isolated from cow milk. Vet Microbiol 2004;98(3-4):307-312. 
55. Diaz AE, Hernández L, Suarez GF. Protection against brucelosis in goats, five years after vaccination with reduced-dose Brucella melitensis Rev-1 vaccine. Tropical Anim health and Prod 2004;3 (2) 117-121.

56. Cantú A, Díaz AE, Hernández AL, Adams GL, y Suárez GF. Estudio epidemiológico de un hato bovino con prevalencia media de brucelosis, vacunado con las mutantes rugosas de Brucella abortus RB51 y rfbk. Vet Mex 2007;38(2):197-206.

57. Fuentes DMD, Vitela MI, Arellano RB, Hernández CR, Morales AJF, Cruz VC. Presence of Brucella abortus vaccinal strain RB51 in vaginal exudates of aborted cows. Res J Dairy Sci 2007;1(1-4):13-17.

58. Leal HM, Díaz AE, Pérez R, Hernández L, Arellano RB, Alfonseca E, et al. Protection of Brucella abortus RB51 vaccine in cows introduced in a herd with active brucellosis, with presence of atypical humoral response. Comp Immunol Microbiol Infect Dis 2005;28(1):63-70.

59. Díaz AE, Arellano RB, Herrera LE, Leal HM, Suárez GF. Characterization of the transitory immune response in cows immunized with RB51 and its implication on diagnosis within brucellosis endemic zones. Intl. J. Dairy Sci 2007;2(4):364-371.

60. Gutiérrez JA, Casanova LG, Romero TC, Sosa GS, Cantó AG, Mercado PM, et al. Population structure of Mycobacterium bovis isolates from cattle in México. Prev Vet Med 2012;106(1):1-8.

61. Norma Oficial Mexicana NOM-031-ZOO-1995. Campaña Nacional Contra la Tuberculosis Bovina (Mycobacterium bovis).1995.

62. Díaz OF, Banda RV, Jaramillo ML, Arriaga DC, González SD Estrada, CC. Identificación de bovinos portadores de Mycobacterium bovis aplicando técnicas inmunológicas y moleculares. Vet Méx 2003;34(1):14-25.

63. Estrada CC, Díaz OF, Arriaga DC, Villegas SN, Pérez GR, González SD. Concordancia de la PCR y métodos rutinarios para el diagnóstico de la tuberculosis bovina. Vet Méx 2004;35(3):225-235.

64. Ramírez CIC, Santillán FMA, Arriaga DC, Arellano RB, Morales AJF. Empleo de la PCR-Multiplex para diferenciar caprinos vacunados con $M$. bovis BCG de infectados con $M$. bovis de campo. Tec Pecu Méx 2004;42(3):419-428.

65. Ramírez CIC, Santillán FMA, Arellano RB, Morales AJF, Tenorio GVR. Detección de secuencias nucleotídicas de Mycobacterium bovis a partir de ADN de moco nasal de caprinos inoculados experimentalmente. Vet Mex 2006;37(2):191-195. 
66. González SDV, Díaz OF, Jaramillo ML, Pérez GR, Padilla UJ, Santillán FMA, et al. Evaluación de diferentes inmunógenos contra la tuberculosis bovina mediante presencia de lesiones a la necropsia. Vet Méx 2007;38(3):271-284.

67. Guzmán RCC, Santillan FMA, Córdova LD. Prevalence and possible risk factors for caprine paratuberculosis in intensive dairy production units in Guanajuato, Mexico. J Vet Med Anim Health 2016;8(11):156-162.

68. Martínez CAG, Santillán FMA, Guzmán RCC, Favila HLC, Córdova LD, Díaz AE, Hernández AL, Blanco OM. Desarrollo de un inmuno ensayo-enzimático (ELISA), para el diagnóstico de paratuberculosis en bovinos. Rev Mex Cienc Pecu 2012;3(1):118.

69. Milián SF, Santillán FMA, Zendejas MH, García CL, Hernández AL, Cantó AG. Prevalence and associated risk factors for Mycobacterium avium subsp. paratuberculosis in dairy cattle in Mexico. J Vet Med Anim Healt 2015;7(10):302-307.

70. Morón CFJ, Cortéz RC, Santillán FMA. Figueroa SB, Gallegos SJ. Prácticas de manejo asociadas con la seroepidemiología de paratuberculosis ovina en San Luis Potosí. Agroproductividad 2015;8(6):30-36.

71. Gallaga MEP, Arellano RB, Santillán FMA, Favila HLC, Córdova LD, Morales RJ, Díaz AE. Situación epidemiológica de la paratuberculosis en las principales regiones caprinas del Estado de Puebla, México. Quehacer Científico en Chiapas 2017;12(1):36-45.

72. Torres VR, Santillán FMA, Córdova LD, Martínez MOL, Guzmán RCC. Comparison of fluorescence polarization assay and enzyme-linked immunosorbent assay for the diagnosis of bovine paratuberculosis. J Vet Med Anim Health 2019;11(5):94-89.

73. Jaimes NG, Santillán FMA, Hernández COA, Córdova LD, Guzmán RCC, Arellano $\mathrm{RB}$, et al. Detección de Mycobacterium avium subespecie paratuberculosis, por medio de PCR-anidada a partir de muestras de heces de ovino. Vet Méx 2008;39(4):377-386.

74. Panciera RJ, Confer AW. Pathogenesis and pathology of bovine pneumonia. Vet Clin Food Anim 2010;(26):191-214.

75. Rivera RJJ, Kisiela D, Czuprynski CJ. Bovine herpesvirus type 1 infection of bovine bronchial epithelial cells increases neutrophil adhesion and activation. Vet Immunol Immunopathol 2009;131(3-4):167-176.

76. Aguilar RF, Trigo TE, Jaramillo ML, Sánchez MH. Aislamiento de Haemophilus somnus a partir de pulmones neumónicos de bovinos. Téc Pecu Méx 1986;(52):67-73. 
77. Trigo TFJ: El Complejo respiratorio infeccioso de los bovinos y ovinos. Ciencia Veterinaria 1987;(4):1-37.

78. Jaramillo ML, Aguilar RF., Trigo TF. Serotipificación de Pasteurella haemolytica y determinación de los tipos cápsulares de Pasteurella multocida, aisladas de pulmones neumónicos de becerros en México. Vet Méx 1987;(18):185-188.

79. Jaramillo ACJ, Hernández CR, Suárez GF, Martínez MJJ, Aguilar RF, Jaramillo ML, Trigo TFJ. Characterization of Mannheimia spp strains isolated from bovine nasal exudate and factors associated to isolates, in dairy farms in the Central Valley of México. Res Vet Sci 2008;84(1):7-13.

80. Salas TE, Aguilar RF, Trigo TF, Jaramillo ML. Sensibilidad de aislamientos de Pasteurella haemolytica y Pasteurella multocida aislados de bovinos y ovinos a varios agentes antimicrobianos. Téc Pecu Méx 1987;25(2):243-249.

81. Pijoán AP, Aguilar RF. Resistencia y sensibilidad a antimicrobianos en cepas de Pasteurella haemolytica, P. multocida y Haemophilus somnus, aisladas en becerras lecheras en establos de Tijuana. Vet Méx 2000; 31(2)154-156.

82. Méndez LM. Detección de leucotoxina en aislamientos de Mannheimia haemolytica obtenidos de exudados nasales y pulmones neumónicos de bovinos productores de leche [Tesis Licenciatura]. México, D.F: Universidad Nacional Autónoma de México; 2010.

83. Pérez RN. Estudio de la capacidad de producción de biopelícula y resistencia a antimicrobianos en cepas de Pasteurella multocida, Mannheimia haemolytica e Histophilus somni [Tesis licenciatura]. México, DF: Universidad Nacional Autónoma de México; 2010.

84. Fernández RMA, Vaca S, Reyes LM, de la Garza M, Aguilar RF, Zenteno E, et al. Outer membrane vesicles of Pasteurella multocida contain virulence factors. Microbiology Open 2014;3(5):711-717.

85. Morales AJF, Jaramillo ML, Oropeza VZ, Tórtora PJ, Espino RG. Evaluación experimental de un inmunógeno de Pasteurella haemolytica en corderos. Vet Mex 1993;24(2):97-105.

86. Aguilar RF, Jaramillo ML, Trigo TF, Suárez GF, Morales AF. Evaluación de la protección contra la pasteurelosis neumónica en corderos vacunados con diferentes antígenos de Pasteurella haemolytica A1. Vet Méx 1997;28(3):221-229. 
87. Jaramillo ML, Aguilar RF, Suárez GF, Trigo TFJ. Challenge exposure of sheep immunized with live vaccine and culture supernatant of Mannheimia haemolytica A1: Effects of revaccination. Small Ruminant Res 2007;70(2-3):209-217.

88. Marquez A, Djelouadji Z, Lattard V, Kodjo A. Overview of laboratory methods to diagnose leptospirosis and to identify and to type leptospires. Int Microbiol 2017;20(4):184-193.

89. Victoriano AF, Smythe LD, Gloriani BN, Cavinta LL, Kasai T, Limpakarnjanarat K, et al. Leptospirosis in the Asia Pacific region. BMC Infect Dis 2009;(9):147. https://doi.org/10.1186/1471-2334-9-147

90. Chideroli RT, Gonçalves DD, Suphoronski SA, Alfieri AF, Alfieri AA, de Oliveira AG, et al. Culture strategies for isolation of fastidious Leptospira Serovar Hardjo and molecular differentiation of genotypes Hardjobovis and Hardjoprajitno. Front Microbiol 2017;(8):2155.

91. Haake DA, Levett PN. Leptospirosis in humans. Curr Top Microbiol Immunol 2015;387:65-97.

92. Barbosa C, Martins G, Lilenbaum W. Infectivity and virulence of leptospiral strains of serogroup Sejroe other than Hardjo on experimentally infected hamsters. Braz J Microbiol 2019;50(4):1129-1132.

93. Ellis WA. Leptospirosis as a cause of reproductive failure. Vet Clin North Am Food Anim Pract 1994;10(3):463-78.

94. Varela G, Roch E. Leptospirosis en la República Mexicana. Salud Públ Méx1965;7(2):189-193.

95. Luna AMA, Moles CLP, Gavaldón RD, Nava VC, Salazar GF. Estudio retrospectivo de seroprevalencia de leptospirosis bovina en México considerando las regiones ecológicas. Rev Cubana Med Trop 2005;57(1):28-31.

96. Cantú CA, Banda RVM. Seroprevalencia de leptospirosis bovina en tres municipios del sur de Tamaulipas. Téc Pecu Méx 1995;33(2):121-124.

97. Carmona GCA, León LL, Castillo SLO, Ramírez OJM, Ko A, Luna PC, et al. Detección de Leptospira santarosai y L. kirschneri en bovinos: nuevos aislados con potencial impacto en producción bovina y salud pública. Vet Méx 2011;42(4):277288.

98. Moles CLP, Cisneros PMA, Gavaldón RD, Rojas SN, Torres BJI. Estudio serológico de leptospirosis bovina en México. Rev Cubana Med Trop 2002;54(1):24-27. 
99. Segura CVM, Solis CJJ, Segura CJC. Seroprevalence of and risk factors for leptospiral antibodies among cattle in the state of Yucatan, Mexico. Trop Anim Health Prod 2003;35(4):293-299.

100. Banda RV, Orozco VL, Urrutia VR. Use of polymerase chain reaction for the identification of Leptospira sp. in urine of carriers. Rev Cubana Med Trop 2005;57(1):47-48.

101. Escamilla HP, Martínez MJJ, Medina CM, Morales SE. Frequency and causes of infectious abortion in a dairy herd in Queretaro, Mexico. Can J Vet Res 2007;(71):314317.

102. Zárate MJP, Rosete FJV, Ríos UA, Barradas PFT, Olazarán JS. Prevalencia de leptospirosis y su relación con la tasa de gestación en bovinos de la zona centro de Veracruz. Nova Scientia 2015;7(14):202-217.

103. Ojeda CJJ, Espinosa AE, Hernández GPA, Rojas MC, Álvarez MJA. Seroprevalencia de enfermedades abortivas de bovinos. Ecosistemas y Recursos Agropecuarios 2016;3(8):243-249.

104. Banda RVM, Loza RE, Mejía SP. Eficiencia del hidróxido de aluminio, vitaminas liposolubles y levamisol, empleados en una bacterina de leptospira en vaquillas, para la generación de anticuerpos específicos. Téc Pecu Méx 1991;29(3):139-143.

105. Orozco VLE, López FR, Moles CLP, Quiroz VJ. Evaluación de una bacterina homóloga contra la leptospirosis bovina. Rev Cubana Med Trop 2005;57(1):38-42.

106. Estrada PA, García Z, Sánchez HF. The distribution and ecological preferences of Boophilus microplus (Acari: Ixodidae) in Mexico. Exp Appl Acarol 2006;38(4):307316.

107. Gaxiola CS, García VZ, Cruz VC, Portillo LJ, Vázquez PC, Quintero MMT, et al. Comparison of efficiency and reproductive aptitude indexes between a reference and field strains of the cattle tick Rhipicephalus (Boophilus) microplus in Sinaloa, Mexico. Rev Bras Parasitol Vet 2009;18(4):9-13.

108. Fernández RM. Comparación de cuatro técnicas de colecta de larvas de Boophilus microplus bajo condiciones de campo en infestación controlada. Tec Pecu Mex 1996;34(3):175-182.

109. Fernandez RM, Cruz VC, Solano VJ, García VZ. Anti-tick effects of Stylosanthes humilis and Stylosanthes hamata on plots experimentally infested with Boophilus microplus larvae in Morelos, Mexico. Exp Appl Acarol 1999;23(2):171-175. 
110. Cruz VC, Fernández RM, Solano VJ, García VZ. Anti-tick effect observed in mature plants of tropical legumes Stylosanthes humilis and S. hamata. Parasitol 1999;23(12):15-18.

111. Fernández RM, Preciado Torre JF, García VZ, Cruz VC, Saltijeral OJ. Evaluación estacional de la recuperación de larvas de Boophilus microplus en cuatro leguminosas forrajeras en parcelas experimentalmente infestadas. Tec Pecu Mex 2004;42(1):97104.

112. Muro CF, Cruz-Vázquez C, Fernández-Ruvalcaba M, Molina-Torres J, Soria CJ, Ramos PM. Repellence of Boophilus microplus larvae in Stylosanthes humilis and Stylosanthes hamata plants. Parasitol Latinoam 2003;58(3-4):118-121.

113. Fernandez RM, Preciado TF, Cruz VC, Garcia VZ. Anti-tick effects of Melinis minutiflora and Andropogon gayanus grasses on plots experimentally infested with Boophilus microplus larvae. Exp Appl Acarol 2004;32(4):293-9.

114. Fernández RM, Zhioua E, García VZ. Infectividad de Metarhizium anisopliae en contra de cepas de garrapata Boophilus microplus sensible y resistente a los organofosforados. Tec Pecu Mex 2005;43(3):433-440.

115. Miranda ME, Cossio BR, Quezada DMR, Sachman RB, Reynaud E. Staphylococcus saprophyticus is a pathogen of the cattle tick Rhipicephalus (Boophilus) microplus. Biocontrol Sci Technol 2010;20(10):1055-1067.

116. Miranda ME, Cossio BR, Martínez IF, Casasanero OR, Folch J. Natural occurrence of lethal aspergillosis in the cattle tick Rhipicephalus (Boophilus) microplus (Acari:Ixodidae). Parasitology 2012;139(2):259-263.

117. Miranda ME, Cossio BR, Tellez AM, García VZ, Rosario CR, Ortiz EM. An enzymatic marker for ixodicide resistance detection in the cattle tick Boophilus microplus. Agric Res 1995;(3):000-008.

118. Rosario CR, Miranda ME, García VZ, Ortiz EM. Detection of esterase activity in susceptible and organophosphate resistant strains of the cattle tick Boophilus microplus (Acari: Ixodidae). Bull Entom Res 1997;87(2):197-202.

119. Hernandez R, He H, Chen AC, Waghela SD, Ivie GW, George JE, Wagner GG. Identification of a point mutation in an esterase gene in different population of the southern cattle tick, Boophilus microplus. Insect Biochem Mol Biol 2000;30(10):969977. 
120. Hernandez R, Guerrero F, George JE, Wagner GG. Allele frequency and gene expression of a putative carboxylesterase-encoding gene in a pyrethroid resistant strain of the tick Boophilus microplus. Insect Biochem Mol Biol 2002;32(9):1009-1016.

121. Pruett JH, Guerrero FD, Hernandez R. Isolation and identification of an esterase from a mexican strain of Boophilus microplus (Acari: Ixodidae). J Econ Entomol 2002;95(5):1001-1007.

122. Guerrero FD, Li AY, Hernandez R. Molecular diagnosis of pyrethroid resistance in mexican strains of Boophilus microplus. J Med Entomol 2002;39(5):770-776.

123. Rosario CR, Guerrero FD, Miller RJ, Rodriguez VRI, Tijerina M, Dominguez GDI, et al. Molecular survey of pyrethroid resistance mechanisms in mexican field population of Rhipicephalus (Boophilus) microplus. Parasitol Res 2009;105(4):1145-1153.

124. Cossio-Bayugar R, Miranda-Miranda E, Ortiz-Najera A, Neri-Orantes S. Boophilus microplus pyrethroid resistance associated to increased levels of monooxygenase enzymatic activity in field isolated Mexican ticks. J Biol Sci 2008;8(2):404-409.

125. Cossio-Bayugar R, Miranda-Miranda E, Ortiz-Najera A, Neri-Orantes S, OlveraValencia F. Cytochrome P-450 monooxygenase gene expression supports a multifactorial origin for acaricide resistance in Ripicephalus microplus. Res J Parasitol 2008;3(2):59-66.

126. Soberanes CN, Santamaria VM, Fragoso SH, Garcia VZ. Primer caso de resistencia al amitraz en la garrapata del ganado Boophilus microplus en México. Tec Pecu Mex 2002;40(1):81-92.

127. Rosado AJA, Rodriguez VRI, Garcia VZ, Fragoso SH, Ortiz NA, Rosario CR. Development of amitraz resistance in field populations of Boophilus microplus (Acari: Ixodidae) undergoing typical amitraz exposure in the Mexican tropics. Vet Parasitol 2008;152(3-4):349-353.

128. Cossio BR, Miranda ME, Portilla SD, Osorio MJ. Quantitative PCR detection of cholinesterase and carboxylesterase expression levels in acaricide resistant Rhipicephalus (Boophilus) microplus. J Entomol 2009;6(2):117-123.

129. Ramírez RPB, Rosario CR, Domínguez GDI, Hernández GR, Lagunes QRE, Ortuño $\mathrm{SD}$, et al. Identification of immunogenic proteins from ovarian tissue and recognized in larval extracts of Rhipicephalus (Boophilus) microplus, through an immunoproteomic approach. Exp Parasitol 2016;170:227-235. 
130. Granjeno CG, Hernandez OR, Mosqueda J, Estrada MS, Figueroa JV, Garcia Vazquez Z. Characterization of a vitellogenin gene fragment in Boophilus microplus ticks. Ann NY Acad Sc 2008;1149(1):58-61.

131. Almazán C, Lagunes R, Villar M, Canales M, Rosario CR, Jongejan F, et al. Identification and characterization of Rhipicephalus (Boophilus) microplus candidate protective antigens for the control of cattle tick infestations. Parasitol Res 2010;(106):471-479.

132. Lugo CCS, Hernandez OR, Gomez RN, Martinez VM, Castro SE, Lagunes QR. Genetic diversity of the ATAQ gene in Rhipicephalus microplus collected in Mexico and implications as anti-tick vaccine. Parasitol Res 2020;(119):3523-3529.

133. Lagunes R, Dominguez D, Quiroz H, Martinez M, Rosario R. Potential effects on Rhipicephalus microplus tick larvae fed on calves immunized with a subolesin peptide predicted by epitope analysis. Trop Biomed 2016;33(4):726-738.

134. Merino CJO, Gómez RN, Barrera MI, Lagunes QR. Análisis in silico del gen subolesina como posible vacuna contra garrapatas Rhipicephalus microplus. Ecosistemas y Recur Agropecuarios 2019;6(16):129-136.

135. Álvarez JA, Figueroa JV. Desarrollo de una vacuna viva atenuada para el control de la babesiosis bovina en México. Servicio Nacional de Sanidad, Inocuidad y Calidad Agroalimentaria. Reunión CENAPA. Morelos, México. 2005:8-15.

136. SIAP. Servicio de información agroalimentaria. 2019.

137. Álvarez JA, Cantó GJ. Epidemiología de la babesiosis. En: H. Quiroz editor Parasitología. Vol. Conmemorativo de la Sociedad Mexicana de Parasitología. S.C. México, D.F.; 1985:55-72.

138. Bock R, Jackson L, De Vos A, Jorgensen W. Bovine babesiosis. Parasitol 2004;(129): 247-269.

139. Rodríguez VRI, Grisi L, Pérez de León AA, Silva VH, Torres AJFJ, Fragoso SH, et al. Evaluación del impacto económico potencial de los parásitos del ganado bovino en México. Rev Mex Cienc Pecu 2017;8(1):61-74.

140. Rodríguez VR, Rivas AL, Chowell G, Fragoso SH, Rosario CR, García Z, et al. Spatial distribution of acaricide profiles Boophilus microplus strains susceptible or resistant to acaricides in southeastern Mexico. Vet Parasitol 2007;146(1-2):158-169.

141. Álvarez MJA, Rojas MC. Hematología diagnóstica. En: Campos RR y Bautista GR editores. Diagnóstico de helmintos y hemoparásitos de rumiantes. AMPAVE; 1989:145-158. 
142. Bolio GME, Figueroa MJV, Álvarez MJA, Rojas MC, Vega MCA, López RM. Examen de laboratorio para parásitos de la sangre. En: Rodríguez-Vivas RI editores. Técnicas para el diagnóstico de parásitos con importancia en salud pública y veterinaria. AMPAVE-CONASA. México, D.F.; 2015:129-157.

143. Alvarez MJA, Rojas MC, Figueroa MJV. Diagnostic tools for the identification of Babesia sp. in persistently infected cattle. Pathogens 2019;8(3):143.

144. Canto AGJ, Figueroa MJV, Ramos AJA, Rojas EE, Garcia TD, Alvarez MJA, et al. Evaluation of cattle inoculated with Babesia bovis clones adhesive in vitro to bovine brain endothelial cells. Ann New York Acad Sci 2006;1081(1):397-404.

145. Nevils MA, Figueroa MJV, Turk JR, Canto AGJ, Le V, Ellersieck MR, et al. Cloned lines of Babesia bovis differ in their ability to induce cerebral babesiosis in cattle. Parasitol Res 2000;86(6):437-443.

146. Figueroa MJV, Alvarez MJA, Buening GM, Cantó AG, Hernandez OR, Monroy B, et al. Antibody Response to Babesia bigemina infection in calves measured ELISA and immunoblotting techniques. Rev Lat Amer Microbiol 1992;34(4):47-55.

147. Rojas RE, Domínguez P, García M, Cruz-Vázquez C, Figueroa MJV, Ramos AJA. Prevalencia e incidencia de Babesia bovis y Babesia bigemina en un hato bovino en Axochiapan, Morelos. Avan Invest Agropec 2004;8(2):1-8.

148. Figueroa MJV, Buening GM, Kinden DA, Green TJ. Identification of common surface antigens among Babesia bigemina isolates using monoclonal antibodies. Parasitol 1990;100(2):161-175.

149. Figueroa MJV, Buening GM, Kinden DA. Use of monoclonal antibodies for the identification of a common surface antigen of Babesia bovis. Ann NY Acad Sci 1998;849(1):433-437.

150. Figueroa MJV, Precigout E, Carcy, B, Gorenflot A. Identification of common antigens in Babesia bovis, B. bigemina, and B. divergens. Ann NY Acad Sci 2006;1081:382396.

151. Figueroa MJV, Precigout E, Carcy B, Gorenflot A. Identification of a coronin-like protein in Babesia species. Ann NY Acad Sci 2006;1026(1):125-38.

152. Goff WL, Johnson WC, Molloy JB, Jorgensen WK, Waldron SJ, Figueroa MJ, et al. Validation of a competitive enzyme-linked immunosorbent assay for detection of Babesia bigemina antibodies in cattle. Clin Vaccine Immunol 2008;15(9):1316-1321. 
153. Ushe TC, Palmer GH, Sotomayor L, Figueroa MJV, Buening GM, Perryman LE, et al. Antibody response to a Babesia bigemina rhoptry-associated protein 1 surface-exposed and neutralization-sensitive epitope in cattle. Infect Immun 1994;62(12):5698-5701.

154. Borgonio V, Mosqueda J, Genis AD, Falcon A, Alvarez JA, Camacho M, et al. msa-1 and msa-2c gene analysis and common epitopes assessment in Mexican Babesia bovis isolates. Ann NY Acad Sci 2008;1149(1):145-148.

155. Perez J, Perez JJ, Vargas P, Alvarez JA, Rojas C, Figueroa JV. Sequence conservation of the 12D3 gene in Mexican isolates of Babesia bovis. Transbound Emerg Dis 2010;57(1-2):57-60.

156. Figueroa MJV, Buening GM, Mishra V, McElwain TF. Screening of a B. bigemina cDNA library with monoclonal antibodies directed to surface antigens. Ann NY Acad Sci 1992b;(653):122-130.

157. Figueroa MJV, Lira AJJ, Vargas UP, Rojas MC, Alvarez MJA. Cloning and sequencing of the rap-1 $1 \alpha 1$ gene from Mexican isolates of Babesia bigemina. J Vet Sci Technol 2017;(8):4.

158. Palacios MJM. Comparación de la prueba de iELISA mediante el uso de las proteínas r12d3 y rRAP-1 como antígeno contra Babesia bigemina. [Tesis licenciatura]. México, Universidad Autónoma del Estado México; 2019.

159. Castañeda ARO, Rojas MC, Figueroa MJV, Álvarez MJA. Ensayo inmunoenzimático con antígeno recombinante MSA-1 para el diagnóstico de Babesia bovis, Memorias VIII Congr Int Epidemiol, León, Gto. 2013:275-279.

160. Castillo PIM, Lira A JJ, Castañeda ARO, Cantú CA, Mejía EF, Polanco MDJ, et al. Comparación de pruebas serológicas para el diagnóstico epidemiológico de babesiosis bovina transmitida por garrapatas. Entomol Mex 2017;4:611-616.

161. Figueroa MJV, Santamaria RM, Lira AJJ, Vargas UP, Castañeda ARO, Alvarez MJA, et al. Determination of the immunogenicity conferred in cattle by inoculation of Babesia bigemina recombinant antigens. J Vet Sci Technol 2018;9. doi:10.4172/21577579-C2-039.

162. Alvarez MJA, Lopez U, Rojas MC, Borgonio VM, Sanchez V, Castaneda ARO, et al. Immunization of Bos taurus steers with Babesia bovis recombinant antigens MSA-1, MSA-2c and 12D3. Transbound Emerg Dis. 2010;57:87-90. 
163. Reyes SRM, Bautista GCR, Castañeda ARO, Vargas U P, Álvarez MJA, Rojas MC, et al. Babesiosis: Field assessment of protection in cattle immunized with a mixture of Babesia bovis recombinant proteins. Quehacer Científico en Chiapas 2016;11(2):3646.

164. Santamaria RM, Lira AJJ, Vargas UP, Álvarez MJA, Rojas MC, Figueroa MJV. Validation of an indirect ELISA using recombinant proteins as antigen to identify animals exposed to Babesia bigemina. Transbound Emerg Dis 2020;67(S2):201-207.

165. Aboytes TR, Buening GM, Figueroa MJV, Vega MCA. El uso de zonas de ADN para el diagnóstico de hemoparásitos. Rev Cubana Cienc Vet 1991;22(3):173-181.

166. Figueroa MJV, Buening GM. Nucleic acid probes as a diagnostic method for tickborne hemoparasites of veterinary importance. Vet Parasitol 1995;57(1-3):75-92.

167. Ramos AJA, Alvarez MJA, Figueroa MJV, Solis J, Rodriguez VRI, Hernandez OR, et al. Evaluation of the use of a Babesia bigemina DNA probe in an epidemiological survey. Mem Inst Oswaldo Cruz 1992;87(3):213-217.

168. Figueroa MJV, Chieves LP, Johnson GS, Buening GM. Detection of Babesia bigemina-infected carriers by polymerase chain reaction amplification. J Clin Microbiol 1992;30(10):2576-2582.

169. Figueroa MJV, Chieves LP, Johnson GS, Goff WL, Buening GM. Polymerase chain reaction-based diagnostic assay to detect cattle chronically infected with Babesia bovis. Rev Lat Amer Microbiol 1994;36(1):47-55.

170. Buening GM, Aboytes TR, Figueroa MJV, Allen LW. A PCR amplification/DNA probe assay to detect Anaplasma marginale carriers. Proc. 96th Ann Meet US Anim Health Assoc. Louisville, Kentucky. 1992:287-294.

171. Figueroa MJV, Chieves LP, Johnson GS, Buening GM. Multiplex polymerase chain reaction assay for the detection of Babesia bigemina, Babesia bovis and Anaplasma marginale DNA. Vet Parasitol 1993;50(1-2):69-81.

172. Figueroa MJV, Alvarez MJA, Ramos AJA, Vega MCA, Buening GM. Use of a multiplex PCR assay to diagnose hemoparasite-infected bovine carriers in Mexico. Revue Élev Méd vét Pays trop 1993;46(1-2):71-75.

173. Alvarez MJA, Ramos AJA, Figueroa MJV, Mosqueda GJJ, Vega MCA, Buening GM. Descriptive epidemiology of anaplasmosis and babesiosis in cattle farms from Campeche Mexico. 75th Ann Meet CRWAD. Chicago, Ill. 1994:56. 
174. Figueroa MJV, Alvarez MJA, Canto AGJ, Ramos AJA, Mosqueda GJJ, Buening GM. Comparative sensitivity of two tests for the diagnosis of multiple hemoparasite infection of cattle. Ann NY Acad Sci 1996;791(1):117-127.

175. López M, Figueroa MJV, Ramos AJA, Mosqueda GJJ, Rojas, REE, Vega MCA, et al. Infection and seroconversion of susceptible animals introduced into a babesiosis endemic area. Ann NY Acad Sci 2008;1149(1):131-135.

176. Figueroa MVJ, Cantó AGJ, Álvarez MJA, Lona R, Ramos AJA, Vega MCA. Capacidad protectora en bovinos de una cepa de Babesia bigemina derivada del cultivo in vitro. Téc Pecu Méx 1998;(36):95-107.

177. Sparagano OAE, Allsopp MTEP, Mank RA, Rijpkema SGT, Figueroa MJV, Jongejan F. Molecular detection of pathogen DNA in ticks: A review. Exp Applied Acarol 1999;23(12):929-960.

178. Rojas RE, Mosqueda GJJ, Álvarez MJA, Hernández OR, Ramos AJ, Rojas MC, et al. Transmissibility of Babesia bigemina and Babesia bovis attenuated strains by Rhipicephalus microplus ticks. Rev Mex Cienc Pecu 2011;2(3):267-281.

179. Figueroa MJV, Lira JJ, Polanco MDJ, Álvarez MJA, Rojas MC, Bautista GCR. Diferenciación de Babesia bovis y Babesia bigemina mediante el uso de una prueba molecular en ADN extraído de garrapatas repletas. Entomol Mex 2015;(2):706-713.

180. Bock RE, de Vos AJ, Lew A, Kingston TG, Fraser IR. Studies on failure of T strain live Babesia bovis vaccine. Aust Vet J 1995;72(8):296-300.

181. Shkap V, de Vos AJ, Zweygarth E, Jongejan F. Attenuated vaccines for tropical theileriosis, babesiosis and heartwater: the continuing necessity. Trends Parasitol 2007;(23):420-426.

182. Shkap V, Kocan K, Molad T, Mazuz M, Leibovich B, Krigel Y, et al. Experimental transmission of field Anaplasma marginale and the A. centrale vaccine strain by Hyalomma excavatum, Rhipicephalus sanguineus and Rhipicephalus (Boophilus) annulatus ticks. Vet Microbiol 2009;134(3-4):254-260.

183. Figueroa MJV, Cantó AGJ, Juárez FJ, Ruiz LF. Cultivo in vitro de Babesia bovis: establecimiento y condiciones óptimas de multiplicación. Téc Pecu Méx 1984;(46):4652.

184. Monroy BM, Romero OG, Torres AR, Álvarez MJA, Canto AGJ, Vega MCA. Establecimiento en México del cultivo in vitro de Babesia bigemina. Téc Pecu Méx 1987;(25):141-50. 
185. Hernández OR, Álvarez MJA, Buening GM, Cantó AGJ, Monroy BM, Ramos AJA, et al. Diferencias en la virulencia y en la inducción de protección de aislamientos de Babesia bigemina derivados de cultivo in vitro. Téc Pecu Méx 1990;28(2):51-61.

186. Cantó AGJ, Figueroa MJV, Álvarez MJA, Ramos AJA, Vega MCA. Capacidad inmunoprotectora de una clona irradiada de Babesia bovis derivada del cultivo in vitro. Téc Pecu Méx 1996;34(3):127-135.

187. Figueroa MVJ, Cantó AGJ, Álvarez MJA, Lona R, Ramos AJA, Vega MCA. Capacidad protectora en bovinos de una cepa de Babesia bigemina derivada del cultivo in vitro. Téc Pecu Méx 1998;36:95-107.

188. Vega MCA, Figueroa MJV, Rojas REE, Ramos AJA, Cantó AGJ. Insuficiente inmunidad cruzada en bovinos por Babesia bigemina y/o Babesia bovis derivadas del cultivo in vitro. Téc Pecu Méx 1999;37(1):13-22.

189. Cantó AG, Figueroa MJV, Ramos AJ, Álvarez MJA, Mosqueda GJJ, Vega MC. Evaluación de la patogenicidad y capacidad protectora de un inmunógeno fresco combinado de Babesia bigemina y B. bovis. Vet Méx 1999;30(3):215-20.

190. Alvarez MJA, Ramos AJA, Rojas RE, Mosqueda GJJ, Vega MCA, Olvera MA, et al. Field challenge of cattle vaccinated with a combined Babesia bovis and Babesia bigemina frozen immunogen. Ann NY Acad Sci 2004;1026(1):277-283.

191. Ojeda JJ, Orozco Flores R, Rojas C, Figueroa JV, Alvarez JA. Validation of an attenuated live vaccine against babesiosis in native cattle in an endemic area. Transboun Emer Dis 2010;57(1-2):84-86.

192. Bautista GCR, Lozano AR, Rojas MC, Alvarez MJA, Figueroa MJV, García GR, et al. Co-immunization of cattle with a vaccine against babesiosis and Lactobacillus casei increases specific IgG1 levels to Babesia bovis and B. bigemina. Parasitol Int 2015;64(5):319-323.

193. Rojas MC, Rodriguez VRI, Figueroa MJ, Acosta VKY, Gutiérrez RJ, Alvarez MJ. In vitro culture of Babesia bovis in a bovine serum-free culture medium supplemented with insulin, transferrin, and selenite. Exp Parasitol 2016;(170):214-219.

194. Rojas MC, Rodriguez VRI, Figueroa MJV, Acosta VKY, Gutiérrez REJ, Alvarez MJA. Putrescine: essential factor for in vitro proliferation of Babesia bovis. Exp Parasitol 2017;(175):79-84. 
195. Rojas MC, Rodriguez VRI, Figueroa MJV, Acosta VKY, Gutiérrez REJ, Bautista GCR, et al. Babesia bigemina: advances in continuous in vitro culture using serum free medium, supplemented with insulin, transferrin, selenite and putrescine. Parasitol Int 2018;67(3):294-301.

196. Rojas MC, Rodriguez VRI, Figueroa MJV, Bautista GCR, Castaneda ARO, Lira AJJ, et al. Bovine babesiosis: Cattle protected in the field with a frozen vaccine containing Babesia bovis and Babesia bigemina cultured in vitro with a serum-free medium. Parasitol Int 2018;67(2):190-195.

197. Brown WC, Palmer GH. Designing blood-stage vaccines against Babesia bovis and B. bigemina. Parasitol Today 1999;15(7):275-281.

198. Álvarez, M.J.A, Figueroa, MJV, Ueti, MW, Rojas MC. Innovative alternatives for continuous in vitro culture of Babesia bigemina in medium free of components of animal origin. Pathogens 2020;9(5):343.

199. Alvarez MJA, Rojas MC, Figueroa MJV. An Overview of current knowledge on in vitro Babesia cultivation for production of live attenuated vaccines for bovine babesiosis in Mexico. Front Vet Sci 2020;(7):364. doi:10.3389/fvets.2020.00364.

200. Mackenzie SJ, Jeggo M. The one health approach. Why is it important? Trop Med Infect Dis 2019;4(2):88. 